\title{
Direct comparisons of ice cloud macro- and microphysical properties simulated by the Community Atmosphere Model version 5 with HIPPO aircraft observations
}

\author{
Chenglai Wu ${ }^{1,2}$, Xiaohong Liu ${ }^{1}$, Minghui Diao ${ }^{3}$, Kai Zhang ${ }^{4}$, Andrew Gettelman ${ }^{5}$, Zheng Lu ${ }^{1}$, Joyce E. Penner ${ }^{6}$, and \\ Zhaohui Lin ${ }^{2}$ \\ ${ }^{1}$ Department of Atmospheric Science, University of Wyoming, Laramie, Wyoming, USA \\ ${ }^{2}$ International Center for Climate and Environment Sciences, Institute of Atmospheric Physics, Chinese Academy of \\ Sciences, Beijing, China \\ ${ }^{3}$ Department of Meteorology and Climate Science, San Jose State University, San Jose, California, USA \\ ${ }^{4}$ Pacific Northwest National Laboratory, Richland, Washington, USA \\ ${ }^{5}$ National Center for Atmospheric Research, Boulder, Colorado, USA \\ ${ }^{6}$ Department of Climate and Space Sciences and Engineering, University of Michigan, Ann Arbor, Michigan, USA
}

Correspondence to: Xiaohong Liu (xliu6@uwyo.edu)

Received: 9 December 2016 - Discussion started: 16 January 2017

Revised: 17 March 2017 - Accepted: 20 March 2017 - Published: 11 April 2017

\begin{abstract}
In this study we evaluate cloud properties simulated by the Community Atmosphere Model version 5 (CAM5) using in situ measurements from the HIAPER Poleto-Pole Observations (HIPPO) campaign for the period of 2009 to 2011. The modeled wind and temperature are nudged towards reanalysis. Model results collocated with HIPPO flight tracks are directly compared with the observations, and model sensitivities to the representations of ice nucleation and growth are also examined. Generally, CAM5 is able to capture specific cloud systems in terms of vertical configuration and horizontal extension. In total, the model reproduces $79.8 \%$ of observed cloud occurrences inside model grid boxes and even higher $(94.3 \%)$ for ice clouds $\left(T \leq-40^{\circ} \mathrm{C}\right)$. The missing cloud occurrences in the model are primarily ascribed to the fact that the model cannot account for the high spatial variability of observed relative humidity (RH). Furthermore, model RH biases are mostly attributed to the discrepancies in water vapor, rather than temperature. At the micro-scale of ice clouds, the model captures the observed increase of ice crystal mean sizes with temperature, albeit with smaller sizes than the observations. The model underestimates the observed ice number concentration $\left(N_{i}\right)$ and ice water content (IWC) for ice crystals larger than $75 \mu \mathrm{m}$ in diameter. Modeled IWC and $N_{i}$ are more sensitive to the threshold diameter for autoconversion of cloud ice to snow
\end{abstract}

$\left(D_{\mathrm{cs}}\right)$, while simulated ice crystal mean size is more sensitive to ice nucleation parameterizations than to $D_{\mathrm{cs}}$. Our results highlight the need for further improvements to the sub-grid RH variability and ice nucleation and growth in the model.

\section{Introduction}

Cirrus clouds, located at high altitudes and composed of ice crystals, are one of the key components in the climate system. They cover about $30 \%$ of the globe (Wang et al., 1996; Wylie and Menzel, 1999). They have a significant impact on the earth's radiation balance via two different effects: scattering and reflecting the incoming shortwave solar radiation back to space, which leads to a cooling effect on the planet, and absorbing and re-emitting terrestrial longwave radiation, leading to a warming effect (Liou, 1986; Ramanathan and Collins, 1991; Corti et al., 2005). The net radiative effect is thus a balance of these two effects and mainly depends on the amount, microphysical, and optical properties of cirrus clouds (Kay et al., 2006; Fusina et al., 2007; Gettelman et al., 2012; Tan et al., 2016). Furthermore, as the efficiency of dehydration at the tropical tropopause layer is strongly influenced by the microphysical processes within cirrus clouds, 
cirrus clouds can also regulate the humidity of air entering the stratosphere and are recognized as an important modulator for water vapor in the upper troposphere and the lower stratosphere (Gettelman et al., 2002; Wang and Penner, 2010; Jensen et al., 2013; Dinh et al., 2014).

Despite their important role in the climate system, there are still large uncertainties in the representation of cirrus clouds in global climate models (GCMs) (Boucher et al., 2013). The uncertainties are the result of several different aspects. First, our understanding of processes initiating the cirrus cloud formation is still limited (DeMott et al., 2003; Kärcher and Spitchtinger, 2009; Hoose and Möhler, 2012). Ice crystals can form via the homogeneous nucleation of soluble aerosol particles and the heterogeneous nucleation associated with insoluble or partly insoluble aerosol particles (e.g., Hagg et al., 2003; Liu and Penner, 2005; Wang and Liu, 2014). Homogeneous nucleation generally requires high ice supersaturation typically of $40-60 \%$ and occurs at temperatures colder than about $-37^{\circ} \mathrm{C}$. It can be fairly well represented by nucleation theory based on laboratory results (Koop et al., 2000). Heterogeneous nucleation is initiated by certain types of aerosols (e.g., mineral dust and biological aerosols) that act as ice nucleating particles (INPs), which can nucleate ice particles at significantly lower ice supersaturations in the environment. Currently there are still large unknowns about the types of aerosol, modes of action (e.g., immersion/condensation, deposition, and contact), and the efficiencies of heterogeneous nucleation in the atmosphere (Hoose and Möhler, 2012). Other ice microphysical processes (e.g., ice aggregation, deposition/sublimation, and sedimentation) as well as interactions among cirrus microphysical properties, macroscopic properties (e.g., spatial extent), and meteorological fields could further render the interpretation of observed ice cloud properties challenging (Diao et al., 2013; Krämer et al., 2016).

In addition to our limited understanding of ice microphysical processes, it is difficult for GCMs with coarse spatial resolution (e.g., tens to hundreds of kilometers in the horizontal direction and a kilometer in the vertical) to capture the sub-grid variability of dynamical and microphysical processes that are vital for ice cloud formation and evolution. The observed microphysical properties of cirrus clouds vary significantly in time and space (e.g., Hoyle et al., 2005; Diao et al., 2013, 2014a; Jensen et al., 2013), associated with variability in relative humidity ( $\mathrm{RH})$, temperature, and vertical wind speed. The spatial extent of clouds is represented in GCMs by diagnosing the cloud fraction in individual model grid boxes using a parameterization. Such a cloud fraction representation needs to be validated with observations in order to identify model biases and to elucidate the reasons behind these biases for future model improvement.

Two types of observational data are currently available for validating modeled cirrus cloud properties: in situ aircraft measurements (e.g., Krämer et al., 2009; Lawson et al., 2011; Diao et al., 2013) and remote-sensing data from spaceborne or ground-based instruments (Mace et al., 2005; Deng et al., 2006, 2008; Li et al., 2012). Remote-sensing data may not be directly comparable to model simulations due to the sampling and algorithmic differences between GCM results and remote-sensing retrievals unless a proper simulator, i.e., a so-called "satellite simulator", is adopted (Bodas-Salcedo et al., 2011; Kay et al., 2012). In situ aircraft observations can provide direct measurements of ice crystal properties such as ice crystal number concentration and size distribution. In particular, these observations are a good source of accurate and high-frequency measurements, and they thus provide a unique tool for constraining GCM cirrus parameterizations (e.g., Zhang et al., 2013; Eidhammer et al., 2014). However, the grid scales of GCMs are much larger than those sampled by in situ observations. Thus direct comparisons at model grid scales are often hindered unless in situ observations are adequately distributed within the grid boxes and can be scaled up. At the micro-scale level of cirrus clouds (subgrid scale), statistical comparisons between model simulations and in situ observations, especially in terms of relationships among cloud microphysical and meteorological variables, are desirable to provide a reliable evaluation of model microphysics (e.g., Zhang et al., 2013; Eidhammer et al., 2014). In addition, aircraft measurements are often limited in their spatial and temporal coverage, which in some sense limits the scope of model-observation comparisons that can be conducted.

Previous studies have focused on the evaluation of cirrus clouds from free-running GCM simulations against in situ observations (e.g., Wang and Penner, 2010; Zhang et al., 2013; Eidhammer et al., 2014). However, since the model meteorology was not constrained by conditions that were representative of the time of the observations, the model biases could not be exclusively ascribed to errors in the cirrus parameterizations. Recently, a nudging technique has been developed to allow the simulated meteorology to be more representative of global reanalysis/analysis fields, and thus the comparison between model simulations and observations is more straightforward for the interpretation and attribution of model biases (Kooperman et al., 2012; K. Zhang et al., 2014). In such simulations, as the meteorology (winds and temperatures) in the GCM are synchronized with observed meteorology, direct comparisons can be achieved by selecting model results that are collocated with observations in space and time, and thus the model outputs can be evaluated in a more rigorous manner.

In this study, we use the in situ aircraft measurements from the National Science Foundation (NSF) HIAPER Pole-toPole Observations (HIPPO) campaign (Wofsy et al., 2011) to evaluate the cloud properties simulated by the Community Atmosphere Model version 5 (CAM5). During the HIPPO campaign, high-resolution $(\sim 230 \mathrm{~m}, 1 \mathrm{~Hz})$ and comprehensive measurements of ambient environmental conditions (such as air temperature, pressure, water vapor, and wind speed), cloud ice crystals, and droplets were obtained. 
HIPPO also provides a nearly pole-to-pole spatial coverage and relatively long flight hours $(\sim 400 \mathrm{~h}$ in total) in various seasons, making it a valuable data set for GCM evaluations. To facilitate the evaluation, CAM5 is run with specified dynamics where the model meteorological fields (horizontal winds $(U, V)$ and temperature $(T))$ are nudged towards the NASA Goddard Earth Observing System Model version 5 (GEOS-5) analysis, while water vapor, cloud hydrometeors, and aerosols are calculated interactively by the model (Larmarque et al., 2012). Moreover, we select collocated CAM5 output along the HIPPO aircraft flight tracks and compare the model simulations and observations directly. Our comparisons focus on cloud occurrence and cloud microphysical properties (e.g., ice water content, number concentration, and size distribution of ice particles) with a specific focus on cirrus clouds. We also investigate the sensitivities of modelsimulated cirrus cloud properties to the ice microphysics parameterizations as well as to the large-scale forcing associated with the nudging strategy.

The remainder of the paper is organized as follows. In Sect. 2, we introduce the HIPPO observational data set and instrumentations. The model simulations and experimental design are described in Sect. 3. In Sect. 4, we examine the model performance in simulating cirrus cloud occurrence and microphysical properties and investigate the reasons behind the model biases. Sensitivities of model results to different nudging strategies are presented in Sect. 5, and discussions and conclusions in Sect. 6.

\section{HIPPO aircraft observations}

The NSF HIPPO Global campaign provided comprehensive observations of clouds and aerosols from $87^{\circ} \mathrm{N}$ to $67^{\circ} \mathrm{S}$ over the Pacific region during 2009 to 2011 (Wofsy et al., 2011). Observations were acquired using the NSF's Gulfstream V (GV) research aircraft, operated by the National Center for Atmospheric Research (NCAR). During this 3-year period, five HIPPO deployments were carried out, with each deployment lasting from 23 days to about 1 month. In total, the HIPPO campaign included 64 flights, 787 vertical profiles (from the surface to up to $14 \mathrm{~km}$ ), and $434 \mathrm{~h}$ of high-rate measurements (http://hippo.ucar.edu). In this study, we use the $1 \mathrm{~Hz}$ in situ measurements of water vapor, temperature, number concentration, and size distribution of ice crystals as well as the number concentration of cloud liquid droplets from HIPPO\#2-5. HIPPO\#1 did not have ice probes on board.

Water vapor was measured by a $25 \mathrm{~Hz}$, open-path verticalcavity surface-emitting laser (VCSEL) hygrometer (Zondlo et al., 2010). The accuracy and precision of water vapor measurements were $\sim 6$ and $\leq 1 \%$, respectively. Temperature $(T)$ was recorded by the Rosemount temperature probe. The accuracy and precision of $T$ measurements were 0.5 and $0.01 \mathrm{~K}$, respectively. Here saturation vapor pressure is calculated following Murphy and Koop (2005), who stated that all the commonly used expressions for the saturation vapor pressure over ice are within $1 \%$ in the range between 170 and $273 \mathrm{~K}$. Then we calculate RH using the saturation vapor pressure with respect to water $\left(T>0{ }^{\circ} \mathrm{C}\right)$ or with respect to ice $\left(T \leq 0^{\circ} \mathrm{C}\right)$. Unless explicitly stated otherwise, we refer to $\mathrm{RH}$ with respect to water when $T>0{ }^{\circ} \mathrm{C}$ and $\mathrm{RH}$ with respect to ice (RHi) when $T \leq 0{ }^{\circ} \mathrm{C}$.

Ice crystal concentrations were measured by the twodimensional cloud particle imaging (2DC) ice probe (Korolev et al., 2011). The 2DC measures ice crystals with a 64diode laser array at $25 \mu \mathrm{m}$ resolution and the corresponding size range of $25-1600 \mu \mathrm{m}$. Outside this range, ice crystals between 1600 and $3200 \mu \mathrm{m}$ are mathematically reconstructed. A quality control was further applied to filter out the particles with sizes below $75 \mu \mathrm{m}$ in order to minimize the shattering effect and optical uncertainties associated with 2DC data. Thus the number concentration $\left(N_{i}\right)$ of ice crystals with diameters from 75 to $3200 \mu \mathrm{m}$ (binned by $25 \mu \mathrm{m}$ ) was derived and is used here for model comparisons. The ice water content (IWC) is derived by integrating the ice crystal mass at each size bin. Mass is calculated from diameter and $N_{i}$ using the mass-dimension (m-D) relationship of Brown and Francis (1995). For the ice crystal size distribution, a gamma function is assumed as in CAM5 (Morrison and Gettelman, 2008):

$\varnothing(D)=N_{0} D^{\mu} \exp (-\lambda D)$,

where $D$ is diameter; $N_{0}$ is the intercept parameter; $\mu$ is the shape parameter, which is set to 0 currently; and $\lambda$ is the slope parameter. The slope and intercept for the observed ice crystal size distributions are obtained by fitting Eq. (1) using the least-squares method as described in Heymsfield et al. (2008). Observed size distributions that provided less than five bins of nonzero concentrations are not considered in order to maintain a reasonable fit, which is similar to what was done in Eidhammer et al. (2014). This removes about $8 \%$ of the total $1 \mathrm{~Hz}$ observations of ice clouds $\left(T \leq-40^{\circ} \mathrm{C}\right)$. Furthermore, we only retain those fitted size distributions that are well correlated with the measured ones, i.e., with a correlation coefficient larger than 0.6 , which leads to a further removal of $10 \%$ of the total $1 \mathrm{~Hz}$ ice crystal measurements. Note that these screenings are applied only for the derivation of the slope and intercept parameters for the ice crystal size distribution.

The cloud droplet number concentration $\left(N_{\mathrm{d}}\right)$ was measured by the Cloud Droplet Probe (CDP) during the HIPPO campaign. The CDP measurement range of cloud droplet diameter is $2-50 \mu \mathrm{m}$. Because $2 \mathrm{DC}$ and CDP probes may report both ice crystals and liquid droplets, we adopted rigorous criteria for the detection of clouds in different temperature ranges. Ninety-nine percent of the observed $N_{i}$ are greater than $0.1 \mathrm{~L}^{-1}$; thus a threshold of $0.1 \mathrm{~L}^{-1}$ is used to define in-cloud conditions. For $T \leq-40^{\circ} \mathrm{C}$, we use the criterion of $N_{i}>0.1 \mathrm{~L}^{-1}$ to detect the occurrence of ice clouds; for $T>-40^{\circ} \mathrm{C}$, the occurrence of clouds, including 
mixed-phase clouds $\left(-40{ }^{\circ} \mathrm{C}<T \leq 0{ }^{\circ} \mathrm{C}\right)$ and warm clouds $\left(T>0{ }^{\circ} \mathrm{C}\right)$, is defined by the conditions of either $N_{i}>0.1 \mathrm{~L}^{-1}$ or $N_{\mathrm{d}}>1 \mathrm{~cm}^{-3}$. Here, we only analyze CDP measurements with $N_{\mathrm{d}}>1 \mathrm{~cm}^{-3}$ to avoid measurement noise as determined by the sensitivity of the instrument.

The HIPPO data set has been previously used for statistical analyses of ice cloud formation conditions and microphysical properties, such as the conditions of the birthplaces of ice clouds - the ice supersaturated regions, the evolutionary trend of RH and $N_{i}$ inside cirrus clouds, and hemispheric differences in these cloud properties (Diao et al., 2013, 2014a, b). In this study, we will use these observations to evaluate CAM5 simulation of ice clouds. We use $10 \mathrm{~s}$ averaged measurements $(\sim 2.3 \mathrm{~km}$ horizontal resolution) which are derived from $1 \mathrm{~Hz}(\sim 230 \mathrm{~m}$ horizontal resolution) observations. Although variations are found (mostly within a factor of 2 and sometimes up to 2-3 for $N_{i}$, IWC, and $\lambda$ ) within $10 \mathrm{~s}$ intervals, the $10 \mathrm{~s}$ averaged observations shown in this study are similar to those based on $1 \mathrm{~s}$ measurements.

\section{Model and experiment design}

\subsection{Model}

This study uses version 5.3 of CAM5 (Neale et al., 2012), the atmospheric component of NCAR Community Earth System Model (CESM). The cloud macrophysics scheme in CAM5 provides an integrated framework for treatment of cloud processes and imposes full consistency between cloud fraction and cloud condensates (Park et al., 2014). Deep cumulus, shallow cumulus, and stratus clouds are assumed to be horizontally distributed in each grid layer without overlapping with each other. Liquid stratus and ice stratus are assumed to have a maximum horizontal overlap with each other. Stratiform microphysical processes are represented by a two-moment cloud microphysics scheme (Morrison and Gettelman et al., 2008; hereafter referred to as version 1 of the MG scheme (MG1)). MG1 was improved by Gettleman et al. (2010) to allow for ice supersaturation. It is coupled with a modal aerosol model (MAM; Liu et al., 2012a) for aerosol-cloud interactions. Cloud droplets can form via the activation of aerosols (Abdul-Razzak and Ghan, 2000). Ice crystals can form via the homogeneous nucleation of sulfate aerosol and/or heterogeneous nucleation of dust aerosol (Liu and Penner, 2005; Liu et al., 2007). The moist turbulence scheme is based on Bretherton and Park (2009). Shallow convection is parameterized following Park and Bretherton (2009), and deep convection is treated following Zhang and McFarlane (1995) with further modifications by Richter and Rasch (2008).

Compared to the default version 5.3, the CAM5.3 version we use includes a version 2 of the MG scheme (MG2) as described by Gettelman and Morrison (2015) and Gettelman et al. (2015). MG2 added prognostic precipitation (i.e., rain and snow) as compared with the diagnostic precipitation in MG1. Note that the current version of the MG scheme treats cloud ice and snow as different categories with their number and mass predicted, respectively (Morrison and Gettelman, 2008). To be consistent with the observations, here the number and mass concentrations of cloud ice and snow are combined together to get the slope parameter $\lambda$ following Eidhammer et al. (2014).

\subsection{Experimental design for model-observation comparisons}

Model experiments are performed using specified dynamics; that is, online-calculated meteorological fields $(U, V$, and $T$ ) are nudged towards the GEOS-5 analysis (the control experiment, referred to as CTL hereafter), while water vapor, hydrometeors, and aerosols are calculated online by the model itself (Larmarque et al., 2012). We also conduct two experiments, one with only $U$ and $V$ nudged (referred to as NUG_UV) and the other with $U, V, T$, and water vapor $(Q)$ nudged (referred to as NUG_UVTQ). These results will be discussed in Sect. 5. The model horizontal and vertical resolutions are $1.9^{\circ} \times 2.5^{\circ}$ and 56 vertical levels, respectively. The time step is $30 \mathrm{~min}$. The critical threshold diameter for autoconversion of cloud ice to snow $\left(D_{\mathrm{cs}}\right)$ was found to be an important parameter affecting ice cloud microphysics (e.g., Zhang et al., 2013; Eidhammer et al., 2014). $D_{\text {cs }}$ is set to $150 \mu \mathrm{m}$ in MG2. We also conduct two sensitive experiments using a value of $75 \mu \mathrm{m}$ (referred to as DCS75) and $300 \mu \mathrm{m}$ (referred to as DCS300) for $D_{\text {cs }}$ (Table 1).

In the standard CAM5 model, homogeneous nucleation takes place on sulfate aerosol in the Aitken mode with diameters greater than $0.1 \mu \mathrm{m}$ (Gettelman et al., 2010). We conduct a sensitivity experiment (referred to as SUL) by removing this size limit (i.e., using all sulfate aerosol particles in the Aitken mode for homogeneous nucleation). Recently, Shi et al. (2015) incorporated the effects of pre-existing ice crystals on ice nucleation in CAM5, simultaneously removing the lower limit of sulfate aerosol size and the upper limit of the sub-grid updraft velocity used for the ice nucleation parameterization. Here a sensitivity experiment (referred to as PRE-ICE) with the Shi et al. (2015) modifications is conducted (Table 1).

We run the model from June 2008 to December 2011 (i.e., 43 months) with the first 7 months as the model spin-up. For direct comparisons between model results and observations, only model output collocated with HIPPO aircraft flights are recorded. That is, we locate the model grid boxes through which the HIPPO aircraft was transecting and then output the model results of these grid boxes at the closest time stamps with respect to the flight time. In total, we have 130577 in situ observation samples at $10 \mathrm{~s}$ resolution $(\sim 363 \mathrm{~h})$ for HIPPO\#2-5. We note that, because the current CAM5 model cannot explicitly resolve the spatiotemporal variability of dynamic fields and cloud properties inside a model grid box, 
Table 1. CAM5 experiments.

\begin{tabular}{lll}
\hline Experiment name & Nudging & Ice microphysics parameterizations \\
\hline CTL & $U, V, T$ & $\begin{array}{l}\text { Threshold diameter for autoconversion of cloud ice to snow } \\
\left(D_{\mathrm{cs}}\right) \text { set to } 150 \mu \mathrm{m}\end{array}$ \\
DCS75 & $U, V, T$ & $\begin{array}{l}\text { As CTL but with } D_{\mathrm{cs}}=75 \mu \mathrm{m} \\
\text { As CTL but with } D_{\mathrm{cs}}=300 \mu \mathrm{m}\end{array}$ \\
DCS300 & $U, V, T$ & $\begin{array}{l}\text { As CTL but without the lower limit }(0.1 \mu \mathrm{m}) \text { for sulfate particle } \\
\text { diameter for homogeneous freezing }\end{array}$ \\
PRE-ICE & $U, V, T$ & $\begin{array}{l}\text { As CTL but with the impacts of pre-existing ice crystals on ice } \\
\text { nucleation (Shi et al., 2015) }\end{array}$ \\
NUG_UV & $U, V, T$ & $\begin{array}{l}\text { As CTL } \\
\text { As CTL }\end{array}$ \\
NUG_UVTQ & $U, V, T, Q$ & A
\end{tabular}

there are inevitably certain caveats in its comparison with in situ observations. For example, as the model time step is $30 \mathrm{~min}$ and horizontal grid spacing is $\sim 200 \mathrm{~km}$, there may be cases where tens to hundreds of flight samples are located within one grid box at a specific time stamp. In this study, we find that there are 1 to 170 observation samples within a model grid box. Therefore, we may over-sample the model results within a model grid box with multiple aircraft samples. However, we note that, because of the specific flight plan of the HIPPO campaign, most of the HIPPO flights were designed to follow a nearly constant direction when flying from one location to the next, and one vertical profile was generally achieved by about every 3 latitudinal degrees. This unique flight pattern combined with the comparatively long flight hours helps to provide a large amount of observation samples transecting through various climate model grid boxes. In total, 635 model grid boxes are used in the direct comparisons with observations. Considering that the actual horizontal area fraction of a model grid box that the aircraft transected through is relatively small, derivations of grid-scale mean observations which can represent the realistic characteristics for the whole grid box are not possible. Nevertheless, we also derive the mean of observations within a model grid box and compare them with model simulations, and the comparison results are similar to those shown in Sect. 4. Note that vertical interpolation is taken to account for the altitude variation of model variables for the direct comparison with aircraft observations.

\section{Results}

\subsection{Cloud occurrence}

In this section, we will first demonstrate the model performance in simulating the spatial distributions of clouds with a case study. Then we will show the overall features of cloud occurrence for all comparison samples. To identify the reasons for the model-observation discrepancies, we will analyze the meteorology conditions (e.g., $T, Q$, and $\mathrm{RH}$ ) and physics processes associated with the formation of clouds. The probability density function (PDF) of ice supersaturation under conditions of clear sky and inside ice clouds will be examined.

\subsubsection{Case study - a specific cloud system}

During HIPPO deployment \#4 and research flight 05, the GV aircraft flew from the Cook Islands to New Zealand over the South Pacific Ocean on 25-26 June 2011 (Fig. 1). Lowlevel clouds existed along almost all the flight tracks at 700$1000 \mathrm{hPa}$, and most of them were warm clouds $\left(T>0{ }^{\circ} \mathrm{C}\right)$. Mid-level (at 400-700 hPa) and high-level clouds (at 250$400 \mathrm{hPa}$ ) were also observed. Generally the model captures well the locations of cloud systems along the flight tracks on 25 June 2011. The simulated ice clouds are located above liquid clouds and extend for thousands of kilometers, which corresponds with the observed mid- to high-level clouds at 250-600 hPa at 22:00-24:00 UTC on 25 June 2011. However, the model misses the low-level clouds observed late on 25 June and early on 26 June and simulates a smaller horizontal extent for the mid-level cloud at 02:30 UTC on 26 June. Overall, the observed clouds on 26 June (further south) were more scattered than those on 25 June. The model is less capable of reproducing these scattered clouds. CAM5 is able to better simulate cloud systems with larger spatial extents, since these systems are controlled by the nudged largescale meteorology.

Figure 2 shows the time series of RH, $Q$, and $T$ during the flight segment shown in Fig. 1. The observations show large spatial variability in RH even during the horizontal flights on 26 June. Overall, the simulated RH is within the range of the observations, but the model is unable to simulate the larger variability, which occurred on sub-grid spatial scales. Both observed and simulated RH values are above $100 \%$ when the model captures the clouds successfully at 22:40-22:50 and 23:10-23:30 UTC on 25 June and at 00:00-00:10 UTC on 26 June (denoted by green vertical bars), although the simulated maximum grid-mean RH value is around $110 \%$, which is $10-30 \%$ less than observed $\mathrm{RH}$ 


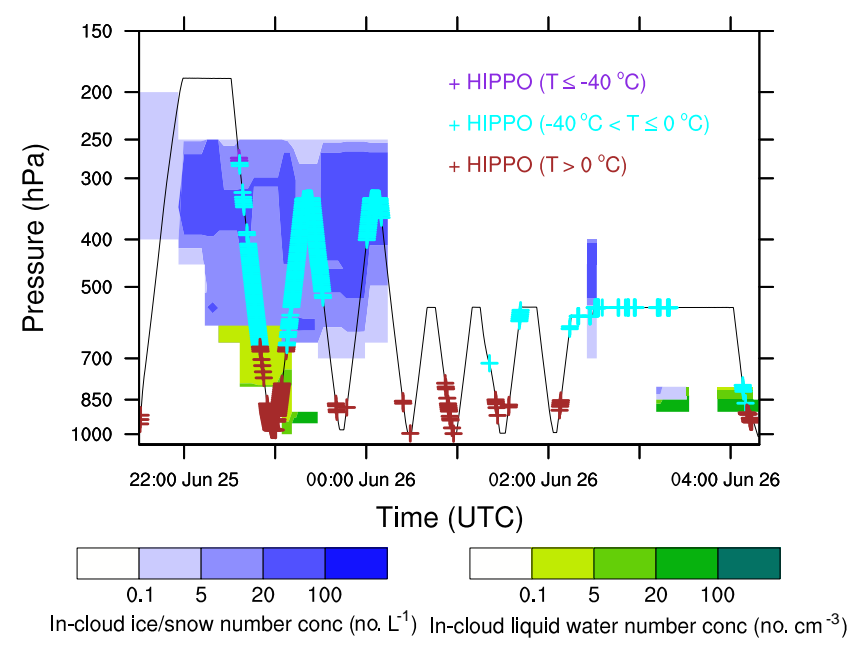

Figure 1. Cloud occurrences simulated by CAM5 (blue and green shaded areas) compared with HIPPO observations (crosses) during HIPPO\#4 research flight 05 (H4RF05) from Rarotonga, the Cook Islands $\left(21.2^{\circ} \mathrm{S}, 159.77^{\circ} \mathrm{W}\right)$, to Christchurch, New Zealand $\left(43.48^{\circ} \mathrm{S}, 172.54^{\circ} \mathrm{E}\right)$, on $25-26$ June 2011 . Modeled in-cloud ice crystal number concentration and cloud droplet number concentration are denoted by blue and green shaded areas, respectively. Three temperature ranges are used to categorize the combined measurements of 2DC and CDP probes. The criteria for defining observed cloud occurrences are described in Sect. 2.

values. However, the model cannot capture some of the observed clouds with large $\mathrm{RH}$ values within the grid boxes. For example, the model misses the RH associated with lowlevel clouds (Fig. 1) at 22:50-23:10 UTC when simulated grid-mean RH values are around $90 \%$ compared to observed values of around $100 \%$. Note that since the aircraft sampled only portions of the model grid boxes, the "overproduction" of cloud occurrences by the model shown in Fig. 2 (blue vertical bars) may not necessarily be the case. Thus we will focus on the cases when the model captures or misses the observed clouds within the model grid boxes.

The spatial distributions of RH play an important role in determining whether modeled clouds occur at the same times and locations as those observed. Biases in either $Q$ or $T$ may lead to discrepancies in RH (Fig. $2 \mathrm{~d}$ and f). For example, at around 21:50 UTC on 25 June, higher RH in the model is caused by the larger simulated $Q$; at 22:50 UTC on 25 June simulated lower RH is mainly caused by the warmer $T$. To illustrate whether $T$ or $Q$ biases are the main cause for the $\mathrm{RH}$ biases, we calculate the offline distribution of RH by replacing the modeled $Q$ and $T$ with the aircraft observations, as shown in Fig. 3a and b, respectively. After adopting the observed $T$ spatial distributions, the updated RH still misses the RH variability around 02:30-04:00 UTC on 26 June, while by adopting the observed $Q$ spatial distribution the updated $\mathrm{RH}$ distribution is very close to the observed one. Thus, in this case study the lack of a large RH spatial variability shown in the observations mainly results from the model's lack of sub-grid-scale variability of $Q$ rather than that of $T$.

\subsubsection{Synthesized analyses on cloud occurrences and cloud fraction}

The overall performance of the model in simulating the cloud occurrences for all flights in HIPPO $2-5$ is shown in Table 2 . In the model, clouds often occupy a fraction of a grid box, and cloud fraction and in-cloud liquid/ice number concentrations are used to represent the occurrence of stratus clouds (Park et al., 2014). For HIPPO, the occurrence of clouds is derived by combining the observations of both liquid and ice number concentrations as described in Sect. 2. In total, the model captures $79.8 \%$ of observed cloud occurrences inside model grid boxes. For different cloud types, the model reproduces the highest fraction $(94.3 \%)$ of observed ice clouds and the second-highest fraction $(86.1 \%)$ of mixedphase clouds. In contrast, the model captures only about half $(49.9 \%)$ of observed warm clouds. As depicted in the case study in Sect. 4.1.1, the lack of cloud occurrences is mainly due to the insufficient representation of sub-grid variability of RH in the model. Next we will further quantify the contribution of sub-grid water vapor and temperature variations to sub-grid variability of RH.

\subsubsection{Decomposition of relative humidity biases}

The formation of liquid droplets/ice crystals depends on dynamical and thermodynamical conditions such as temperature, water vapor, and updraft velocity (Abdul-Razzak and Ghan, 2000; Liu et al., 2007, 2012b; Gettelman et al., 2010). The fraction of liquid / ice stratus clouds is calculated empirically from the grid-mean RH (Park et al., 2014). Thus RH is an important factor for model representations both of cloud occurrences and cloud fraction. RH is a function of pressure, temperature, and water vapor. Since we only compare observations with the simulation results on the same pressure levels, differences of RH $(d \mathrm{RH})$ between simulations and observations (i.e., model biases in RH) only result from the differences in temperature and water vapor. We calculate the contributions of biases in water vapor and temperature to the biases in RH following the method that was used to analyze $\mathrm{RH}$ spatial variability in Diao et al. (2014a). $\mathrm{RH}_{\mathrm{o}}$ (observations) and $\mathrm{RH}_{\mathrm{m}}$ (model results) are calculated as

$\mathrm{RH}_{\mathrm{o}}=\frac{e_{\mathrm{o}}}{e_{\mathrm{s}, \mathrm{o}}}, \quad \mathrm{RH}_{\mathrm{m}}=\frac{e_{\mathrm{m}}}{e_{\mathrm{s}, \mathrm{m}}}$,

where $e_{\mathrm{o}}$ and $e_{\mathrm{m}}$ are observed and simulated water vapor partial pressure, respectively, and $e_{\mathrm{s}, \mathrm{o}}$ and $e_{\mathrm{s}, \mathrm{m}}$ are observed and simulated saturation vapor pressure over ice $\left(T \leq 0^{\circ} \mathrm{C}\right)$ or over water $\left(T>0{ }^{\circ} \mathrm{C}\right)$ in the observations and the model, respectively.

Here $d \mathrm{RH}$ is calculated from the difference of simulated grid-mean RH (with vertical variances taken into account by 

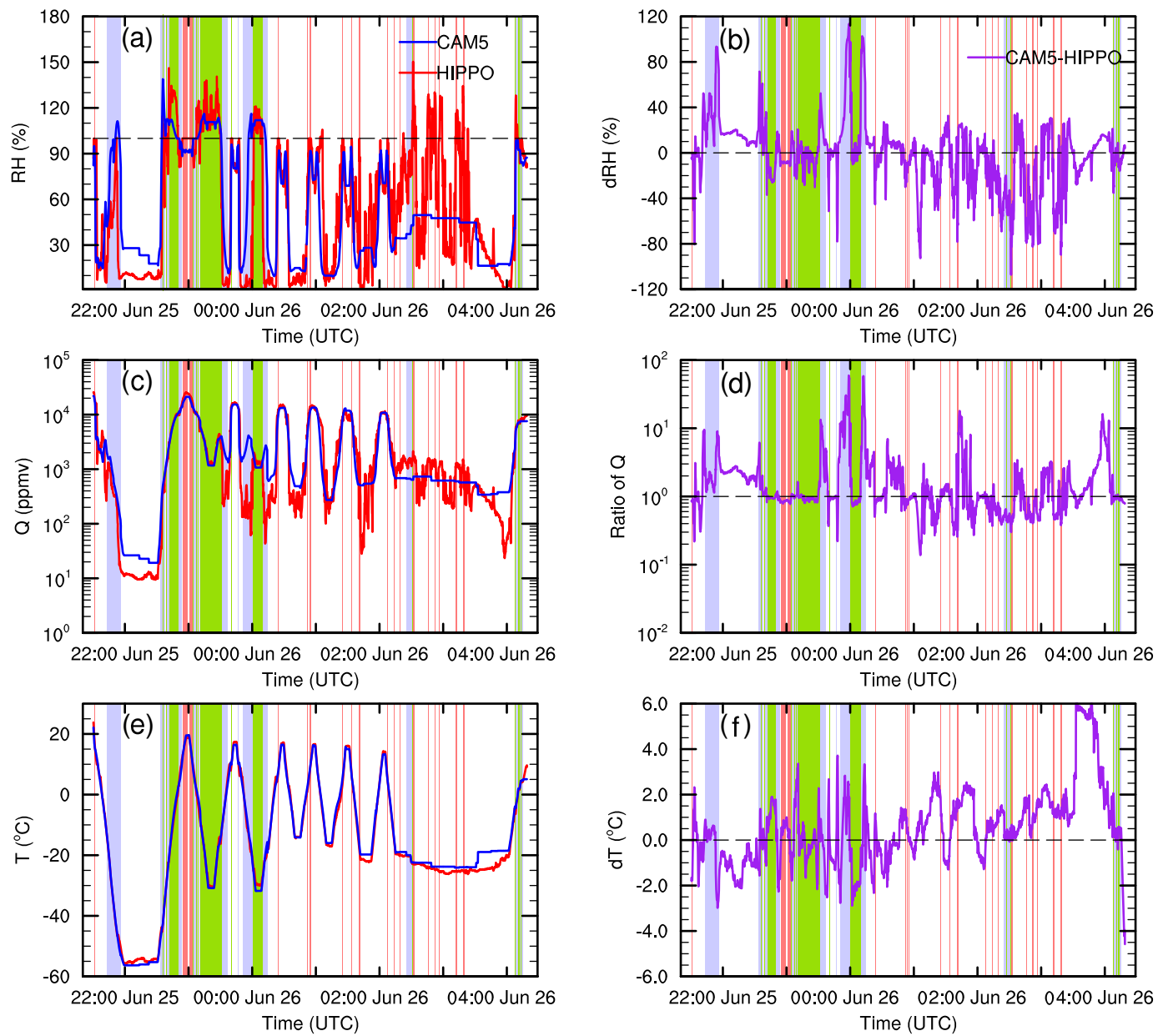

Figure 2. Spatial variabilities of RH, water vapor $(Q)$, and temperature $(T)$ from CAM5 simulation and HIPPO observation (left), and their differences (right). Absolute difference between CAM5 and HIPPO is shown for RH and $T$, while the ratio between CAM5 and HIPPO is shown for $Q$. Model performances are denoted by shaded vertical bars: green (red) denotes when the model captures (misses) the observed cloud occurrences, and blue denotes when the model simulates a cloud that is not present in the observation.

Table 2. The numbers of cloud occurrences in the $10 \mathrm{~s}$ averaged observations $\left(N_{\text {obs }}\right)$, as well as those that CAM5 captures $\left(N_{\text {cap }}\right)$ or misses ( $\left.N_{\text {mis }}\right)$ within the model grid boxes for different temperature ranges. The ratio of $N_{\text {cap }}$ and $N_{\text {mis }}$ to $N_{\text {obs }}$ are given in parenthesis next to them.

\begin{tabular}{llrrr}
\hline Cloud type & Temperature ranges & $N_{\text {obs }}$ & $N_{\text {cap }}$ & $N_{\text {mis }}$ \\
\hline Ice cloud & $T \leq-40^{\circ} \mathrm{C}$ & 3101 & $2925(94.3 \%)$ & $176(5.7 \%)$ \\
Mixed-phase cloud & $-40^{\circ} \mathrm{C}<T \leq 0^{\circ} \mathrm{C}$ & 8768 & $7546(86.1 \%)$ & $1222(13.9 \%)$ \\
Warm cloud & $T>00^{\circ} \mathrm{C}$ & 3334 & $1665(49.9 \%)$ & $1669(50.1 \%)$ \\
All & & 15203 & $12136(79.8 \%)$ & $3067(20.2 \%)$ \\
\hline
\end{tabular}

the vertical interpolation) and in situ observations. We define $d e=\left(e_{\mathrm{m}}-e_{\mathrm{o}}\right)$ and $d\left(\frac{1}{e_{\mathrm{s}}}\right)=\frac{1}{e_{\mathrm{s}, \mathrm{m}}}-\frac{1}{e_{\mathrm{s}, \mathrm{o}}} ;$ therefore $d \mathrm{RH}$ is

$d \mathrm{RH}=\mathrm{RH}_{\mathrm{m}}-\mathrm{RH}_{\mathrm{o}}=d e \cdot \frac{1}{e_{\mathrm{s}, \mathrm{o}}}+e_{\mathrm{o}} \cdot d\left(\frac{1}{e_{\mathrm{s}}}\right)+d e \cdot d\left(\frac{1}{e_{\mathrm{s}}}\right)$.

Thus $d \mathrm{RH}$ can be separated into three terms: the first term is the contribution from the water vapor partial pressure $\left(d \mathrm{RH}_{q}\right)$, the second term from temperature $\left(d \mathrm{RH}_{T}\right)$, and the third term from concurrent impact of biases in temperature and water vapor $\left(d \mathrm{RH}_{q, T}\right)$.

Figure 4 shows the contributions of these three terms to $d \mathrm{RH}$ for different temperature ranges. All the three terms as well as $d \mathrm{RH}$ are given in percentage. The intercepts and slopes of linear regression lines for $d \mathrm{RH}_{q}$ versus $d \mathrm{RH}$, $d \mathrm{RH}_{T}$ versus $d \mathrm{RH}$, and $d \mathrm{RH}_{T, q}$ versus $d \mathrm{RH}$ are also presented. As temperature is constrained by GEOS-5 analy- 

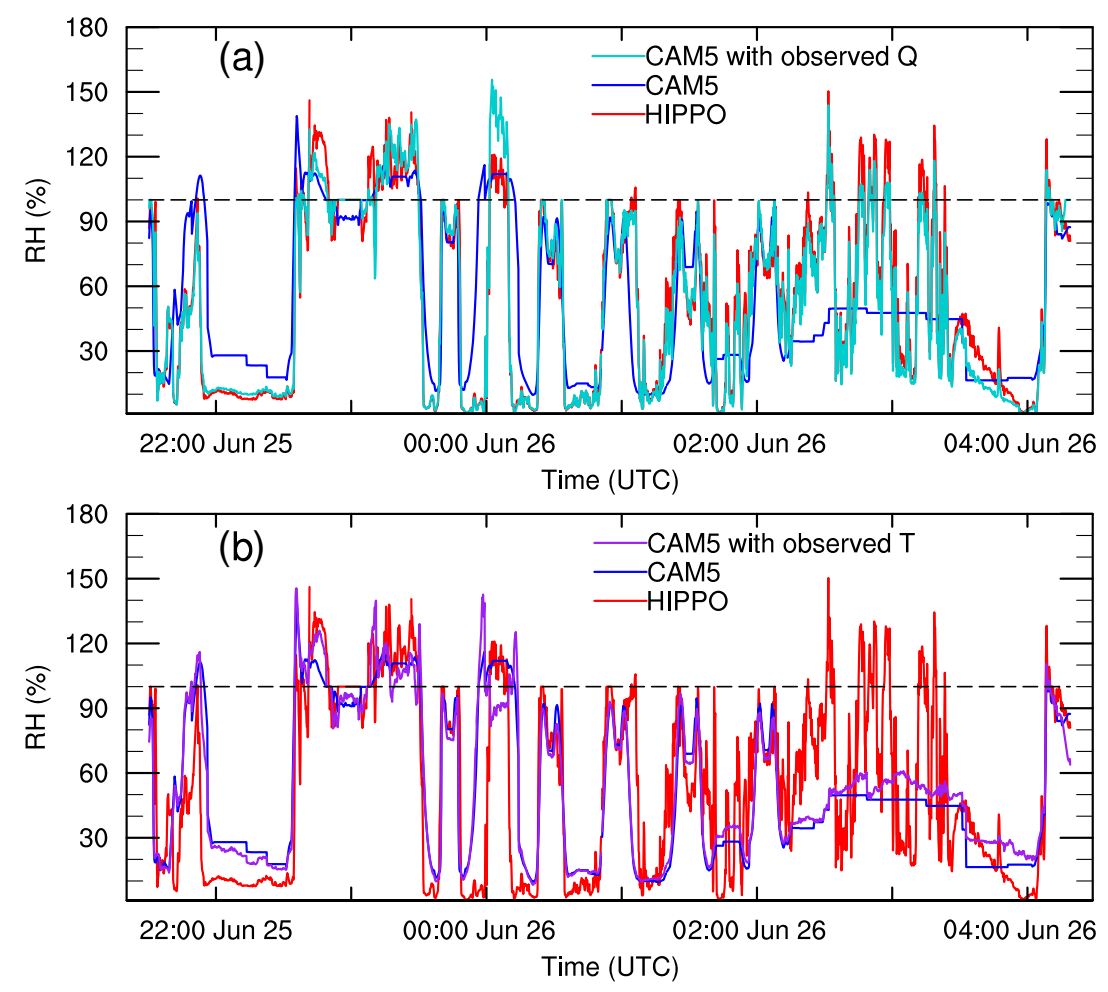

Figure 3. As Fig. 2a but for RH recalculated by replacing the model output with either (a) observed $Q$ or (b) observed $T$ values.

sis, the bias in temperature is reduced (although not eliminated) to mostly within $\pm 7^{\circ} \mathrm{C}$. A considerable amount of discrepancy in RH exists between model and observations. The model successfully captures the clouds (green symbols) when the simulated RH is close to observations in all the three temperature ranges. The model tends to miss the clouds (red symbols) when lower RH is simulated and produces spurious clouds (blue symbols) when higher $\mathrm{RH}$ is simulated. Regarding the contributions of $d \mathrm{RH}_{q}$ and $d \mathrm{RH}_{T}$ to $d \mathrm{RH}$, the slopes of the linear regression for $d \mathrm{RH}_{q}$ versus $d \mathrm{RH}$ are $0.748,0.933$, and 0.786 for $T \leq-40^{\circ} \mathrm{C},-40^{\circ} \mathrm{C}<T \leq 0{ }^{\circ} \mathrm{C}$, and $T>0{ }^{\circ} \mathrm{C}$, respectively, which are much larger than those for $d \mathrm{RH}_{T}$ versus $d \mathrm{RH}(0.087,0.072$, and 0.210 for the three temperature ranges, respectively). This indicates that most of the biases in $\mathrm{RH}$ are contributed by the biases in water vapor $\left(d \mathrm{RH}_{q}\right)$. However, for $T>0{ }^{\circ} \mathrm{C}$, although $d \mathrm{RH}_{q}$ still dominates, $d \mathrm{RH}_{T}$ contributes notably to $21 \%$ of the $\mathrm{RH}$ biases. For $T \leq-40^{\circ} \mathrm{C}, d \mathrm{RH}_{q, T}$ also contributes about $17 \%$ to $d \mathrm{RH}$, indicating concurrent impact from biases of temperature and water vapor. In contrast, for $-40{ }^{\circ} \mathrm{C}<T \leq 0{ }^{\circ} \mathrm{C}$ and $T>0{ }^{\circ} \mathrm{C}$, the contributions of $d \mathrm{RH}_{q, T}$ to $d \mathrm{RH}$ are negligible. We note that the slopes of linear regression lines for $d \mathrm{RH}_{q}$ versus $d \mathrm{RH}$ and $d \mathrm{RH}_{T}$ versus $d \mathrm{RH}$ indicate the average contributions from water vapor and temperature biases to the RH biases, respectively. The values of $d \mathrm{RH}_{T}$ can occasionally reach up to $\pm 100 \%$, which suggests the large impact from temperature biases in these cases. In addition, the $d \mathrm{RH}_{T}$ and $d \mathrm{RH}_{q}$ terms can have the same (opposite) signs, which would lead to larger (lower) total biases in RH. The coefficients of determination, $R^{2}$, for the linear regressions indicate that $d \mathrm{RH}_{q}$ versus $d \mathrm{RH}$ has a much stronger correlation than that of $d \mathrm{RH}_{T}$ versus $d \mathrm{RH}$.

\subsubsection{Ice supersaturation}

Ice nucleation only occurs in the regions where ice supersaturation exists. Different magnitudes of ice supersaturation are required to initiate homogeneous and heterogeneous nucleation (Liu and Penner, 2005). The distribution of ice supersaturation may provide insights into the mechanisms for ice crystal formation (e.g., Haag et al., 2003). In CAM5, ice supersaturation is allowed (Gettelman et al., 2010). Homogeneous nucleation occurs when $T \leq-35^{\circ} \mathrm{C}$ and ice supersaturation reaches a threshold ranging from 145 to $175 \%$. Dust aerosol can serve as INPs when RH $>120 \%$. Ice supersaturation will be relaxed back to saturation via the vapor deposition process (Liu et al., 2007; Gettelman et al., 2010).

To examine the discrepancies in ice supersaturation between model results and observations, we compare the distribution of RH for conditions of clear sky and within cirrus clouds (Fig. 5). The analysis is limited to the conditions of $T \leq-40^{\circ} \mathrm{C}$ for both model simulations and observations. In CAM5, RH diagnosed in different sections of the time integration procedure can be different due to the time-splitting 

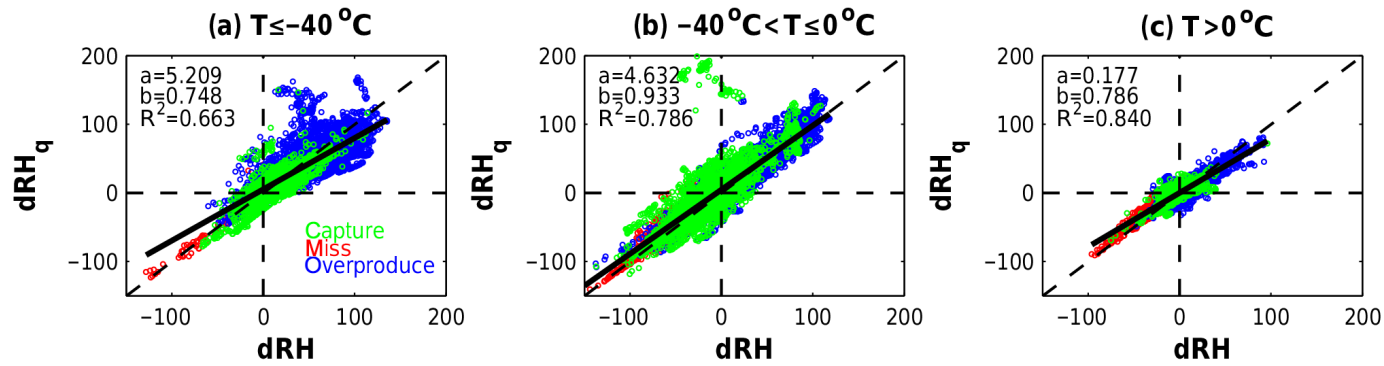

(d) $\mathrm{T} \leq-40^{\circ} \mathrm{C}$

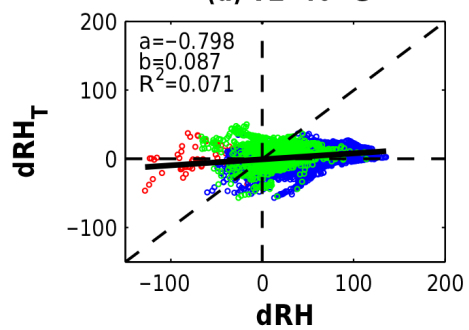

(e) $-40^{\circ} \mathrm{C}<\mathrm{T} \leq 0^{\circ} \mathrm{C}$
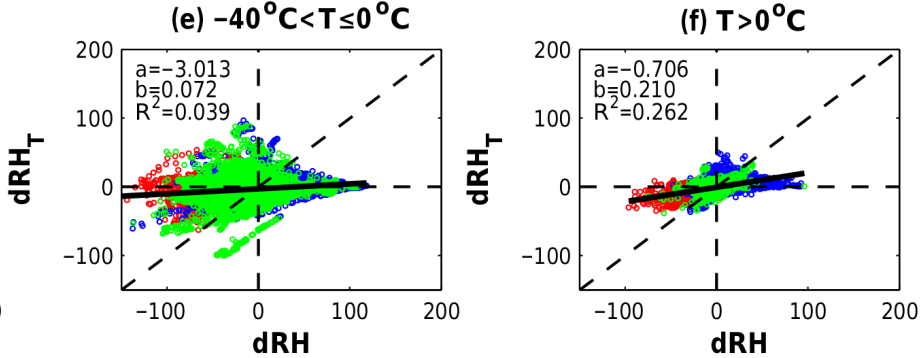

(g) $\mathrm{T} \leq-40^{\circ} \mathrm{C}$
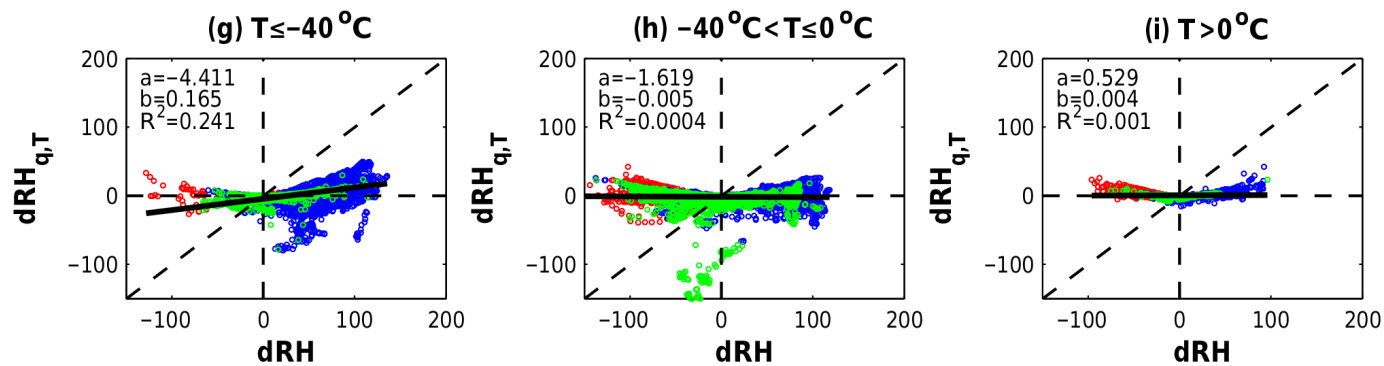

Figure 4. Corresponding (top) $d \mathrm{RH}_{q}$ versus $d \mathrm{RH}$, (middle) $d \mathrm{RH}_{T}$ versus $d \mathrm{RH}$, and (bottom) $d \mathrm{RH}_{q, T}$ versus $d \mathrm{RH}$ (unit: \%) for different temperature ranges. The colors indicate three types of model performances in simulating clouds as described in Fig. 2: green ("captured"), red ("missed"), and blue ("overproduced"). The black lines denote the linear regressions of the samples (i.e., $Y=a+b \times X$ ), and the intercept (i.e., $a$ ) and slope (i.e., $b$ ) of the regression lines as well as the coefficient of determination (i.e., $R^{2}$ ) are shown in the legend.

algorithm. We present here the RH both before and after the microphysical processes.

The observations show that ice supersaturation exists in both clear-sky and inside-cirrus conditions. In clear-sky environments, the PDF of RH shows a continuous decrease with $\mathrm{RH}$ values in subsaturated conditions, followed by a quasiexponential decrease with the $\mathrm{RH}$ above saturation. The maximum RHi reaches up to $150 \%$. In cirrus clouds, most RH values range from 50 to $150 \%$ with a peak in the PDF near $100 \%$. This feature is consistent with the results of Diao et al. (2014b), who used $1 \mathrm{~s}$ HIPPO measurements and separated the Southern and the Northern Hemisphere for comparison.

The PDFs of modeled RH before and after the microphysical processes are very similar except that the latter one has slightly lower probability of RHi above $140 \%$ for insidecirrus conditions. The model is capable of simulating the occurrences of ice supersaturation in both clear-sky and incloud conditions. However, inside cirrus clouds, the simulated PDF of RH peaks around $120 \%$ instead of $100 \%$ as observed. Outside the cirrus clouds (clear sky), the model simulates a much lower probability of ice supersaturation with the maximum RH value around $120 \%$. The largest ice supersaturation simulated by CAM5 under clear-sky conditions is around $20 \%$, which corresponds to the ice supersaturation of $20 \%$ assumed in the model for the activation of heterogeneous nucleation. This indicates the dominant mode of heterogeneous nucleation in the model. However, the observations show much higher frequencies of ice supersaturations larger than $20 \%$, indicating higher RH thresholds for homogeneous nucleation or heterogeneous nucleation.

\subsection{Microphysical properties of ice clouds}

Together with cirrus cloud fraction, the ice crystal number concentration and size distribution within cirrus clouds determine the radiative forcing of cirrus clouds. In this section, we will present the evaluation of modeled microphysical properties of cirrus clouds for $T \leq-40^{\circ} \mathrm{C}$. As measurements of ice crystal number concentration include both ice and snow crystals, for comparison with observations, we combine the cloud ice and snow simulated in the model (hereafter referred to as ice crystals). Following Eidhammer et al. (2014), the slope and intercept parameters of the gamma function for the ice 
(a) Clear-sky, $\mathrm{T} \leq-40^{\circ} \mathrm{C}$

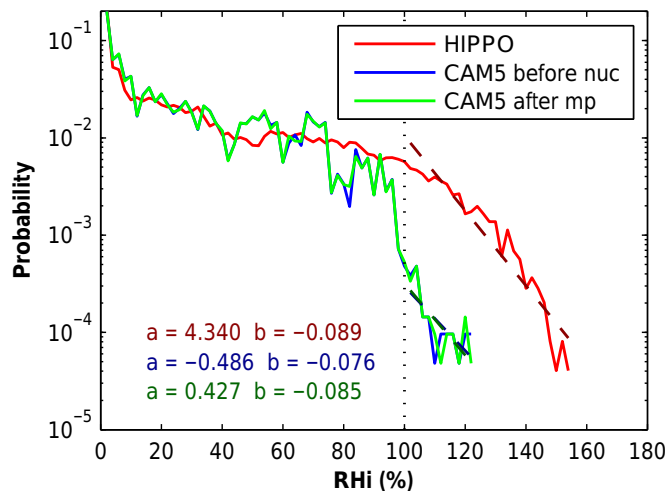

(b) In-cloud, $\mathrm{T} \leq-40^{\circ} \mathrm{C}$

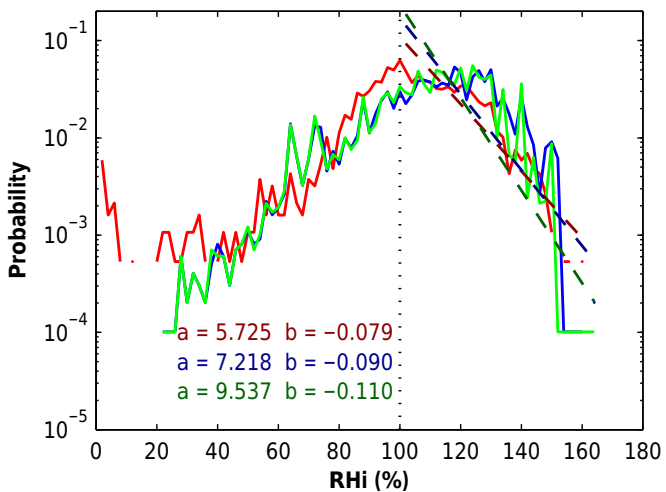

Figure 5. Observed and simulated probability density functions (PDFs) of relative humidity with respect to ice (RHi; unit: $\%$ ) for $T \leq-40^{\circ} \mathrm{C}$ separated into clear-sky and in-cirrus conditions. PDFs of RHi before and after cloud microphysics in the simulations are both shown. The RHi is binned by $2 \%$ for the calculation of PDF. The PDFs (when RHi $>100 \%$ ) follow an exponent decay: $\ln (\mathrm{PDF})=a+b \times \mathrm{RHi}$. The values of $a$ and $b$ for each PDF are also shown in dark red (observed), dark blue (simulated before ice nucleation), and dark green (simulated after cloud microphysics). Note blue lines are mostly invisible as overlaid by green lines.

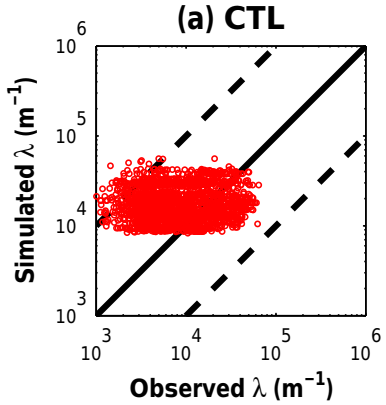

(d) SUL

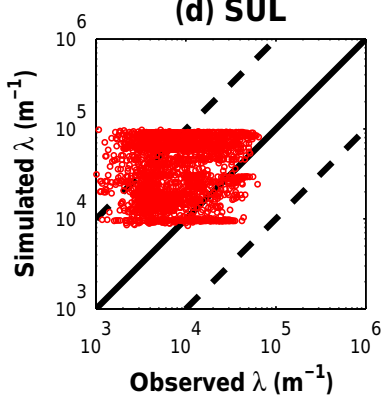

(b) DCS75

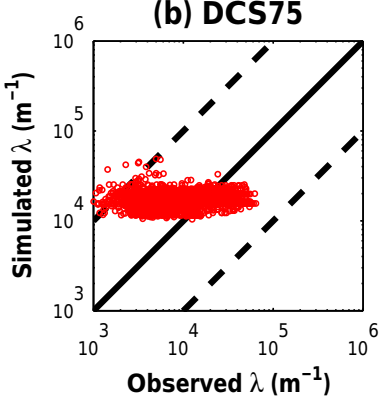

(e) PRE-ICE



(c) DCS300

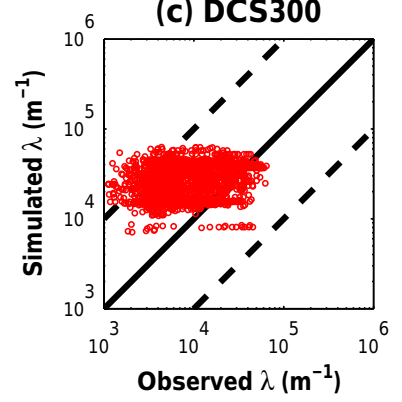

(f) Frequency for each range

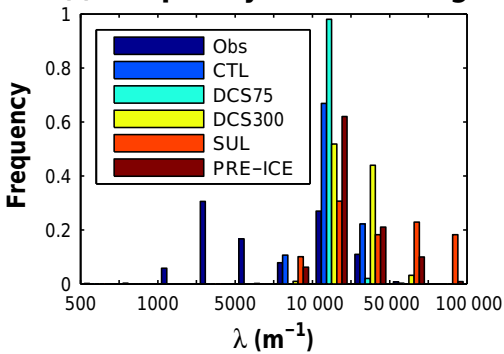

Figure 6. (a-e) Scatterplot of observed versus simulated slope parameter $(\lambda)$ of the gamma size distribution function for each experiment, and (f) the frequency of $\lambda$ for each range. Note that all the comparisons are restricted to the cases when the model captures observed ice clouds $\left(T \leq-40^{\circ} \mathrm{C}\right)$.

crystal size distribution simulated by the model are derived from the total number concentration and mass mixing ratio of cloud ice and snow, which are the integrations of the first and third moments of the size distribution function. The simulated number concentration of ice crystals with sizes larger than $75 \mu \mathrm{m}$ is calculated by the integration of gamma size distributions from $75 \mu \mathrm{m}$ to infinity. The simulated IWC for ice crystals with sizes larger than $75 \mu \mathrm{m}$ is also derived by integrating the mass concentration of cloud ice and snow from
$75 \mu \mathrm{m}$ to infinity. We note that about $94 \%$ of total cirrus cloud samples are at temperatures between -60 and $-40^{\circ} \mathrm{C}$.

\subsubsection{Ice crystal size distribution}

Direct comparison of the slope parameter $(\lambda)$ for ice crystal size distributions is shown in Fig. 6. The slope parameter $\lambda$ determines the decay rate of a gamma function in relation to the increasing diameter. With a larger $\lambda$, the decay of a gamma function with increasing size is faster, and there 
are relatively fewer large ice crystals. The number-weighted mean diameter can be defined as the inverse of $\lambda$ (i.e., $\lambda^{-1}$ ). As shown in Fig. 6, the observed $\lambda$ is generally within the range from $10^{3}$ to $10^{5} \mathrm{~m}^{-1}$. The model reproduces the magnitude of $\lambda$ for some of the observations but tends to overestimate the observations for smaller $\lambda$ values $\left(10^{3}\right.$ to $\left.10^{4} \mathrm{~m}^{-1}\right)$. This indicates that the model produces higher fractions of ice crystals at smaller sizes, and the number-weighted mean diameter is underestimated. Moreover, the model generally simulates $\lambda$ in a narrower range of $7.5 \times 10^{3}$ to $7 \times 10^{4} \mathrm{~m}^{-1}$ for the three experiments with different $D_{\mathrm{cs}}(\mathrm{CTL}, \mathrm{DCS} 75$, and DCS300). SUL and PRE-ICE simulate a wider range of $\lambda$, which is comparable to the observations but tends to shift $\lambda$ to larger values $\left(5 \times 10^{4}\right.$ to $\left.1 \times 10^{5} \mathrm{~m}^{-1}\right)$. All the experiments rarely simulate the occurrence of small $\lambda$ (below $7.5 \times 10^{3} \mathrm{~m}^{-1}$ ).

Figure 7 shows the relationship of $\lambda$ with temperature from observations and model simulations. Here, both the geometric means and the standard deviations of $\lambda$ for each temperature interval of $4{ }^{\circ} \mathrm{C}$ are also shown. Although the observed $\lambda$ does not monotonically decrease with increasing temperature, overall decreasing trend can be found for the whole temperature range below $-40{ }^{\circ} \mathrm{C}$. This indicates a general increase in the number-weighted mean diameter of ice crystals with increasing temperature. The correlation between $\lambda$ and temperature from HIPPO is similar to that from the Atmospheric Radiation Measurements Spring Cloud Intensive Operational Period in 2000 (ARM-IOP) and the Tropical Composition, Cloud and Climate Coupling (TC4) campaigns as shown in Eidhammer et al. (2014), but the HIPPO observations extend to lower temperatures than ARM-IOP and TC4 observations, where temperatures are mostly above $-56{ }^{\circ} \mathrm{C}$. In addition, HIPPO observations show a broader scatter range of $\lambda$, which may be because HIPPO sampled ice crystals at various environment conditions as the flight tracks covered much wider areas and lasted for much longer periods. The decrease of $\lambda$ with increasing temperature has been shown in many other studies (e.g., Heymsfield et al., 2008, 2013). Such a feature is mainly due to more small ice particles at lower temperatures, which can be explained by less water vapor available for ice crystal growth as well as more ice crystals formed from nucleation (more likely from homogeneous nucleation than from heterogeneous nucleation) at lower temperatures (Eidhammer et al., 2014).

Compared to the observations, the simulated mean $\lambda$ is about 2-4 times larger for all the experiments, indicating that the model simulates smaller mean sizes for ice crystals. The simulated $\lambda$ decreases with increasing temperature, which is generally consistent with the observations. In addition, the geometric standard deviations (less than 2) of simulated $\lambda$ are smaller than observed (around 2-3). This can be partly explained by the fact that in situ observations sampled the sub-grid variability of cloud properties.

The difference of simulated $\lambda$ is within a factor of 2 among the five experiments when temperature is between -40 and

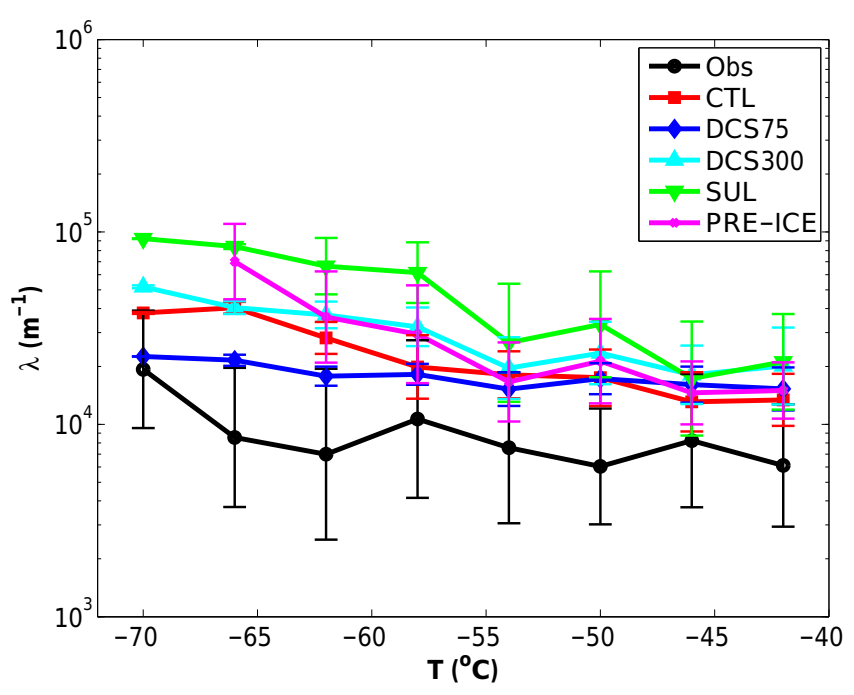

Figure 7. $\lambda$ versus temperature from the measurements and simulations. The lines are the geometric mean binned by $4{ }^{\circ} \mathrm{C}$, with the vertical bars denoting the geometric standard deviation. Note that the comparisons are restricted to the cases when the model captures the observed ice clouds $\left(T \leq-40^{\circ} \mathrm{C}\right)$.

$-56{ }^{\circ} \mathrm{C}$, and it is larger (around 2-4) when temperature is below $-56^{\circ} \mathrm{C}$. For the experiments with different $D_{\mathrm{cs}}$, CTLand DCS75-simulated $\lambda$ are close to each other when temperature is between -40 and $-60^{\circ} \mathrm{C}$, and DCS300 simulates larger $\lambda$ compared to DCS75 and CTL. For temperatures between -64 and $-72{ }^{\circ} \mathrm{C}, \mathrm{CTL}$ - and DCS300-simulated $\lambda$ are close to each other and both are larger than that of DCS75. For the experiments with different ice nucleation parameterizations, both SUL and PRE-ICE simulate larger $\lambda$ than CTL especially for temperatures below $-56^{\circ} \mathrm{C}$. SUL simulates the largest $\lambda$ of all the experiments. This can be explained by much larger number concentration of ice crystals (for all size range; figure not shown) simulated by SUL, while IWC is not very different from other experiments (Sect. 4.2.3).

\subsubsection{Ice crystal number concentration}

Figure 8 shows the comparison of in-cloud number concentrations $\left(N_{i}\right)$ of ice crystals with diameters larger than $75 \mu \mathrm{m}$ between observations and simulations. The magnitude of observed $N_{i}$ varies by 3 orders of magnitude from $10^{-1}$ to $10^{2} \mathrm{~L}^{-1}$. The model simulates reasonably well the range of $N_{i}$ in cirrus clouds. However, the model tends to underestimate $N_{i}$ for all the experiments except DCS75. About 13 (DCS75) to $30 \%$ (PRE-ICE) of observations are underestimated in the model by a factor of 10 . The underestimation of $N_{i}$ may be partly attributed to the fact that the model underestimates the ice crystal size (Sect. 4.2.1), leading to a smaller fraction of ice crystals with diameters larger than $75 \mu \mathrm{m}$. Additional bias may result from the bias in the total ice crystal number concentration, although the observa- 
(a) CTL

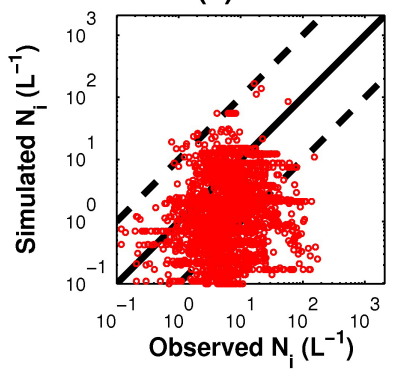

(d) SUL

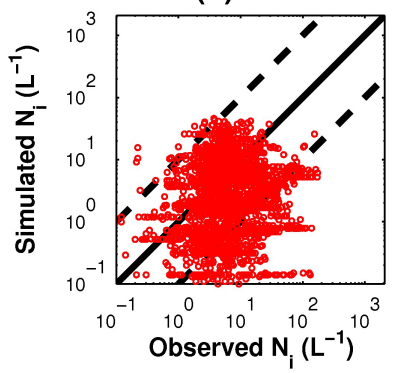

(b) DCS75

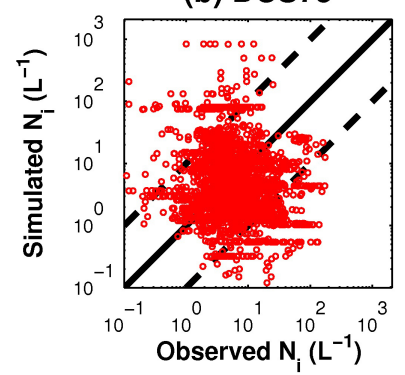

(e) PRE-ICE

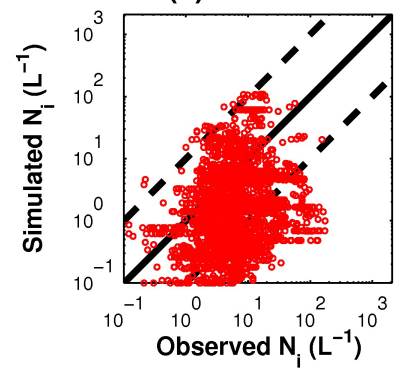

(c) DCS300

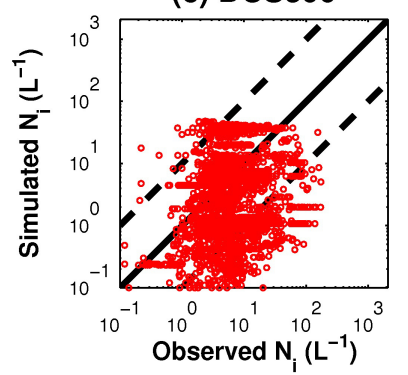

(f) Frequency for each range

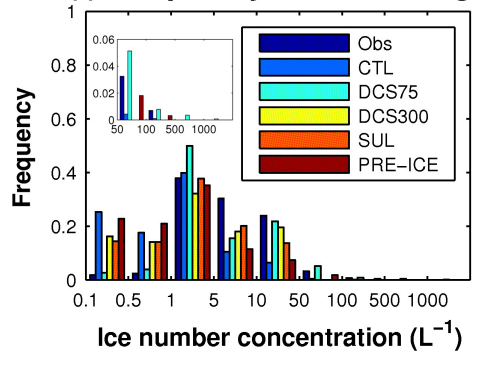

Figure 8. As Fig. 6 but for the number concentrations $\left(N_{i}\right)$ of ice crystals with diameters larger than $75 \mu \mathrm{m}$ for all the experiments. The inset in (f) is the frequency of $N_{i}$ plotted for $N_{i}>50 \mathrm{~L}^{-1}$. Note that both the comparisons are restricted to the cases when the model captures observed ice clouds $\left(T \leq-40^{\circ} \mathrm{C}\right)$.

tions are not available for comparison. We also compare simulated $N_{i}$ with observed in-cloud $N_{i}$ averaged within the model grid boxes. We choose the flight segments with over $3001 \mathrm{~s}$ aircraft measurements within an individual model grid and calculate the average for in-cloud $N_{i}$ of ice clouds $\left(T \leq-40^{\circ} \mathrm{C}\right)$. The comparison results are, however, similar to those shown in Fig. 8.

DCS75 reasonably simulates the occurrence frequency of $N_{i}<1 \mathrm{~L}^{-1}$ albeit with significantly higher frequency for $N_{i}$ around $1-5 \mathrm{~L}^{-1}$ and lower frequency for $N_{i}$ around 5$10 \mathrm{~L}^{-1}$. Most of the experiments cannot reproduce the occurrence frequency of high $N_{i}\left(N_{i}>50 \mathrm{~L}^{-1}\right)$ except DCS75 and PRE-ICE.

The relationships between $N_{i}$ and temperature are shown in Fig. 9. Since $N_{i}$ here only takes into account ice crystals larger than $75 \mu \mathrm{m}$, the geometric mean of observed $N_{i}$ generally ranges between 5 and $10 \mathrm{~L}^{-1}$ for temperatures below $-40^{\circ} \mathrm{C}$, which is $1-2$ orders of magnitude lower than the number of ice crystals between 0.3 and $775 \mu \mathrm{m}$ from observations complied by Krämer et al. (2009) and between 10 and $3000 \mu \mathrm{m}$ from the SPARTICUS campaign (Zhang et al., 2013) but is comparable to the number of ice crystals in the same size range from the ARM-IOP and TC4 campaigns (Eidhammer et al., 2014). The geometric standard deviation of observed $N_{i}$ within a temperature interval of $4{ }^{\circ} \mathrm{C}$ can be as high as a factor of 5 .

The model simulates no apparent trends of $N_{i}$ when temperature decreases from -40 to $-60^{\circ} \mathrm{C}$ for the experiments CTL, DCS75, and PRE-ICE. The model somehow simulates

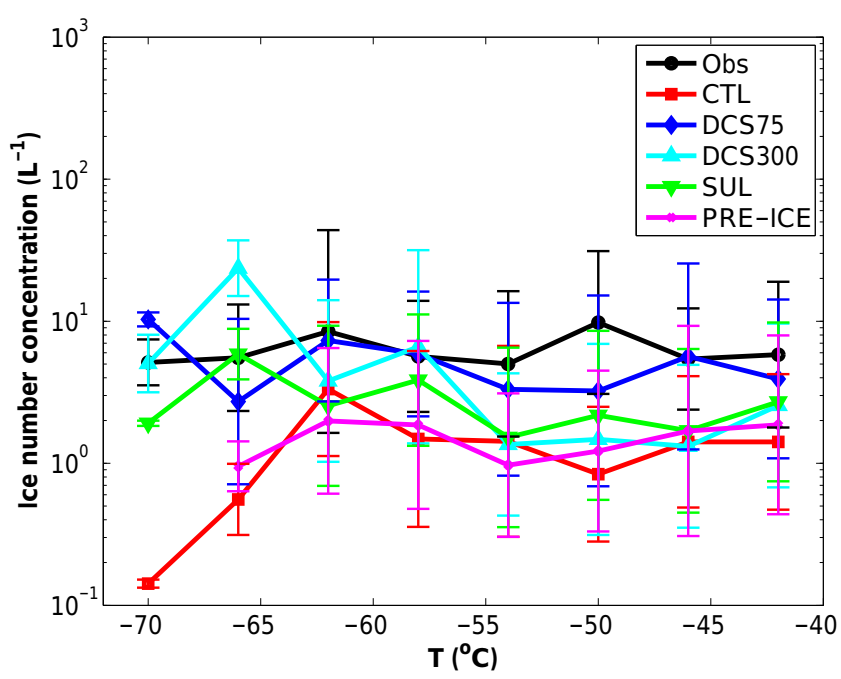

Figure 9. As Fig. 7 but for $N_{i}$.

larger $N_{i}$ with decreasing temperatures for the experiments DCS300 and SUL. Increase of $N_{i}$ at lower temperatures in SUL may indicate the occurrence of homogeneous nucleation. Overall, simulated $N_{i}$ is sensitive to $D_{\mathrm{cs}}$. Simulated $N_{i}$ is also sensitive to the number of sulfate aerosol particles for homogeneous nucleation. With the removal of the lower size limit $(0.1 \mu \mathrm{m}$ diameter) of sulfate aerosol particles for homogeneous nucleation in the experiment SUL, simulated $N_{i}$ is significantly higher than that in CTL because of the substantial increase in the total ice crystal number con- 


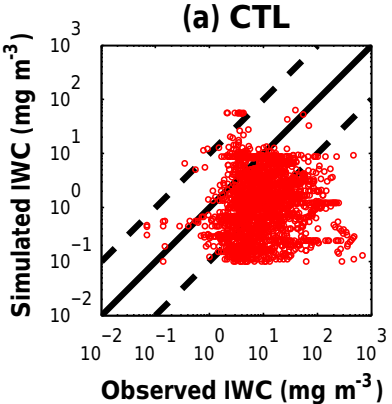

(d) SUL

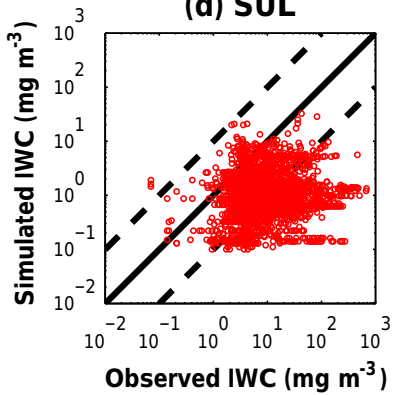

(b) DCS75

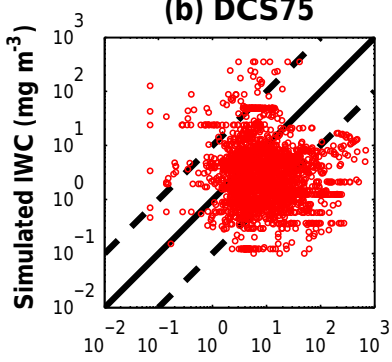

Observed IWC $\left(\mathrm{mg} \mathrm{m}^{-3}\right)$

(e) PRE-ICE

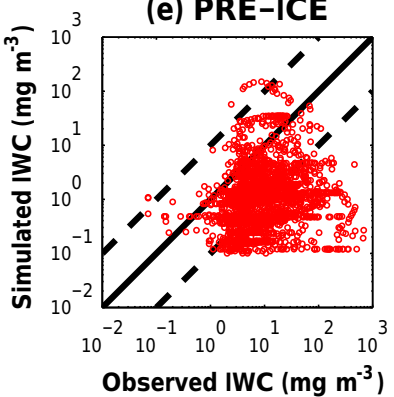

(c) DCS300

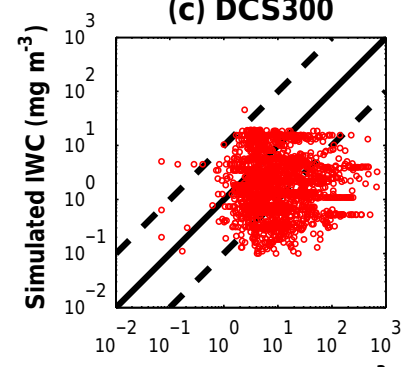

Observed IWC $\left(\mathrm{mg} \mathrm{m}^{-3}\right)$

(f) Frequency for each range

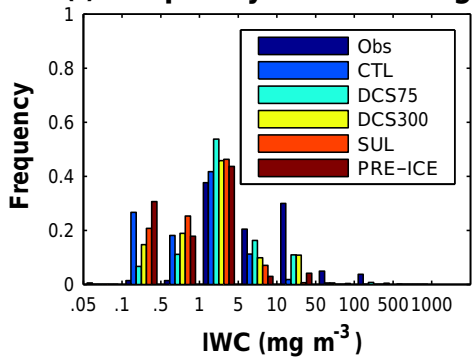

Figure 10. As Fig. 8 but for the comparison of ice water content (IWC).

centration in SUL, although the slope parameter in SUL is larger, indicating a smaller fraction of ice crystals with larger sizes (e.g., larger than $75 \mu \mathrm{m}$ ). This result is consistent with that of Wang et al. (2014).

Although some experiments can simulate a similar magnitude of $N_{i}$ as the observations in some temperature ranges, most of the experiments underestimate $N_{i}$, and some experiments (CTL and PRE-ICE) underestimate $N_{i}$ for all the temperature ranges. Overall DCS75 simulates the closest magnitude of $N_{i}$ with the observations for temperatures from -40 to $-64{ }^{\circ} \mathrm{C}$.

\subsubsection{Ice water content}

Figure 10 shows the comparison of in-cloud IWC for ice crystals with diameters larger than $75 \mu \mathrm{m}$ between observations and simulations. The magnitude of observed IWC varies by 4 orders of magnitude from $10^{-2}$ to $10^{2} \mathrm{mg} \mathrm{m}^{-3}$, which is within the range of observed IWC in previous studies (Kramer et al., 2016; Luebke et al., 2016). Observed IWC here is mostly larger than $1 \mathrm{mg} \mathrm{m}^{-3}$. Compared to the observations, the model for all the experiments underestimates observed IWC for 70-95\% of the samples and by 1 order of magnitude for $25-45 \%$ of the samples. Although the model reproduces the highest occurrence frequency of IWC around $1-5 \mathrm{mg} \mathrm{m}^{-3}$, the model simulates more occurrence of IWC below $1 \mathrm{mg} \mathrm{m}^{-3}$ and fewer occurrence of IWC above $5 \mathrm{mg} \mathrm{m}^{-3}$.

The relationships between IWC and temperature are shown in Fig. 11. An overall increasing trend of observed IWC with temperature is found for the entire temperature range. The observed relationship between IWC and temperature is consistent with those shown in the previous studies (e.g., Kramer et al., 2016; Luebke et al., 2016). However, the mean IWC from HIPPO is 3-5 times as large as previous observations (Kramer et al., 2016; Luebke et al., 2016). Observations here only account for ice crystals with diameters larger than $75 \mu \mathrm{m}$, and thus it is less frequent that observed IWC is lower than $1 \mathrm{mg} \mathrm{m}^{-3}$. In contrast, previous studies showed that IWC (including smaller sizes of ice crystals) lower than $1 \mathrm{mg} \mathrm{m}^{-3}$ was often measured in observations. This contributes to the mean IWC shown here being larger than that in the previous studies.

The simulated IWC is lower than observations for all the experiments at temperatures between -40 and $-60^{\circ} \mathrm{C}$, at which most of the observations were made. The model also simulates less variation of IWC with temperature when temperature is between -40 and $-60^{\circ} \mathrm{C}$. When temperature is below $-60^{\circ} \mathrm{C}$, a steep decrease of IWC is found in some experiments (e.g., CTL, SUL). Considering the large scatter of IWC and relatively few samples available, this may be due to a lack of a sufficient number of samples. Therefore, more observations are needed to have a robust comparison for relatively low temperatures (i.e., temperatures below $-60^{\circ} \mathrm{C}$ ). Simulated IWC is more sensitive to $D_{\mathrm{cs}}$ than to ice nucleation.

\section{Impact of nudging}

In previous sections, we have nudged the simulated winds and temperature towards the GEOS-5 analysis but kept the water vapor online-calculated by the model itself. We showed 
Table 3. The intercepts and slopes of the regression lines (i.e., $Y=a+b \times X$ ) for $d \mathrm{RH}_{q}$ versus $d \mathrm{RH} d \mathrm{RH}_{T}$ versus $d \mathrm{RH}$, and $d \mathrm{RH}_{q, T}$ versus $d$ RH in the three experiments CTL, NUG_UV, and NUG_UVTQ, respectively. The coefficients of determination (i.e., $R^{2}$ ) for each regression line are also presented.

\begin{tabular}{|c|c|c|c|c|c|c|c|c|c|c|}
\hline & & \multicolumn{3}{|c|}{$T \leq-40^{\circ} \mathrm{C}$} & \multicolumn{3}{|c|}{$-40^{\circ} \mathrm{C}<T \leq 0^{\circ} \mathrm{C}$} & \multicolumn{3}{|c|}{$T>0^{\circ} \mathrm{C}$} \\
\hline & & $a$ & $b$ & $R^{2}$ & $a$ & $b$ & $R^{2}$ & $a$ & $b$ & $R^{2}$ \\
\hline \multirow[t]{3}{*}{ CTL } & $d \mathrm{RH}_{q}$ & 5.209 & 0.748 & 0.663 & 4.632 & 0.933 & 0.786 & 0.177 & 0.786 & 0.840 \\
\hline & $d \mathrm{RH}_{T}$ & -0.798 & 0.087 & 0.071 & -3.013 & 0.072 & 0.039 & -0.706 & 0.210 & 0.262 \\
\hline & $d \mathrm{RH}_{q, T}$ & -4.411 & 0.165 & 0.241 & -1.619 & -0.005 & 0.0004 & 0.529 & 0.004 & 0.001 \\
\hline \multirow[t]{3}{*}{ NUG_UV } & $d \mathrm{RH}_{q}$ & -16.85 & 0.723 & 0.562 & -5.589 & 0.866 & 0.614 & -5.207 & 0.658 & 0.698 \\
\hline & $d \mathrm{RH}_{T}$ & 29.96 & -0.103 & 0.024 & 10.09 & -0.013 & .0005 & 4.804 & 0.265 & 0.188 \\
\hline & $d \mathrm{RH}_{q, T}$ & -13.11 & 0.380 & 0.487 & -4.498 & 0.148 & 0.088 & 0.402 & 0.078 & 0.085 \\
\hline \multirow[t]{3}{*}{ NUG_UVTQ } & $d \mathrm{RH}_{q}$ & -2.851 & 0.813 & 0.770 & 2.260 & 0.925 & 0.672 & -1.773 & 0.733 & 0.761 \\
\hline & $d \mathrm{RH}_{T}$ & 3.964 & 0.073 & 0.040 & -0.265 & 0.094 & 0.038 & 1.892 & 0.308 & 0.311 \\
\hline & $d \mathrm{RH}_{q, T}$ & -1.113 & 0.114 & 0.262 & -1.996 & -0.019 & 0.003 & -0.119 & -0.041 & 0.095 \\
\hline
\end{tabular}

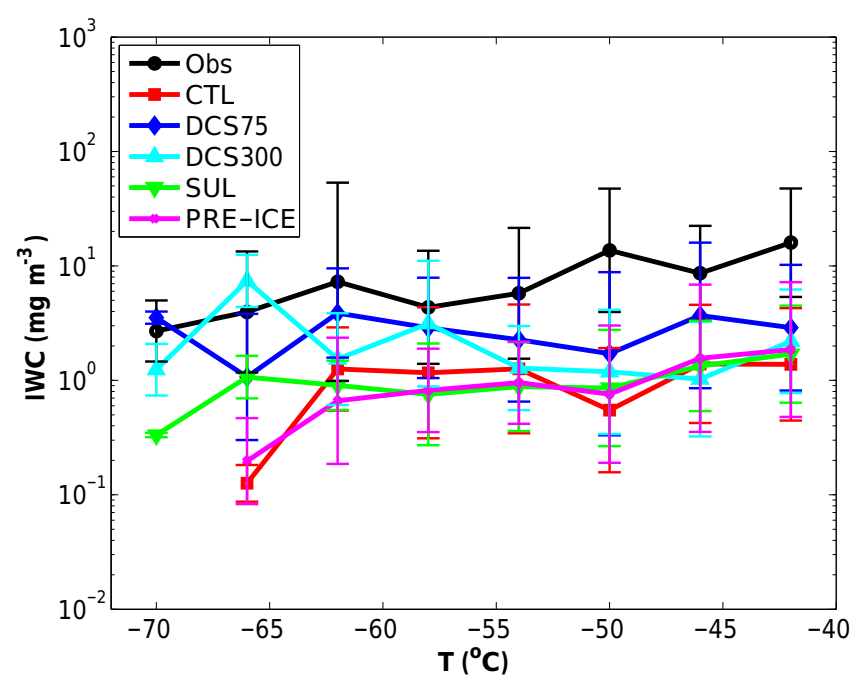

Figure 11. As Fig. 9 but for ice water content (IWC) versus temperature.

that the model captures a large portion $(79.8 \%)$ of cloud occurrences presented in the observations. We also identified the RH bias in the simulation and attributed the RH bias mainly to the bias in water vapor. As the bias in temperature is reduced in the nudging run compared to the free run, the attribution of RH bias in the free-running model (i.e., no nudging applied) is still unclear. To examine the impact of nudging strategies on the cloud occurrences and the attribution of RH bias, we conducted two additional experiments: one with neither temperature nor specific humidity nudged towards the analysis (hereafter referred to as NUG_UV), and the other one with both temperature and specific humidity nudged towards the analysis (hereafter referred to as NUG_UVTQ). Without nudging temperature, the model experiment (NUG_UV) has a cold temperature bias of $-1.8^{\circ} \mathrm{C}$ on average relative to the HIPPO observations (figure not shown). In comparison, the temperatures simulated by CTL and NUG_UVTQ are more consistent with in situ aircraft observations, and the mean temperature is slightly underestimated by 0.22 and $0.28^{\circ} \mathrm{C}$ in these two experiments, respectively. By nudging specific humidity, the model experiment (NUG_UVTQ) improves the simulation of grid-mean water vapor concentrations by eliminating the biases especially for the cases with low water vapor concentrations (less than 20 ppmv; figure not shown). NUG_UV captures 86.0, 80.9, and $39.7 \%$ of observed ice, mixed-phase, and warm clouds, respectively, which are slightly smaller than those of CTL (i.e., 94.3, 86.1, and 49.9\%, respectively). For NUG_UVTQ, although $73.5 \%$ of ice clouds are captured, the model captures only $61.8 \%$ of mixed-phase clouds and $31.4 \%$ of warm clouds. The worse simulation in NUG_UVTQ may be because the nudged water vapor is not internally consistent with the modeled cloud physics, which deteriorates the simulation of cloud occurrences. The bias in cloud occurrences may also be related to the RH threshold values used in the cloud fraction scheme in the model (Park et al., 2014), and further study is needed to address the model sensitivity to the RH threshold values.

As seen in Table 3, in the two new nudging experiments (NUG_UV and NUG_UVTQ), modeled RH biases in the comparison with in situ observations also mainly result from the discrepancies of water vapor. The contribution of $d \mathrm{RH}_{q}$ to $d \mathrm{RH}$ ranges from 65.8 to $92.5 \%$, which are slightly smaller than those in CTL. In NUG_UV, as the model underestimates the temperature, modeled $\mathrm{RH}$ is systematically higher than observations, especially for $T \leq$ $-40^{\circ} \mathrm{C}$, at which temperature the absolute value of $\mathrm{RH}$ is overestimated by $30 \%$ on average. The large $T$ bias leads to a smaller contribution from the water vapor bias $\left(d \mathrm{RH}_{q}\right)$ and a larger contribution from the concurrent bias in temperature and water vapor $\left(d \mathrm{RH}_{q, T}\right)$. When both $T$ and $Q$ are nudged 
in NUG_UVTQ, the contributions of the three terms to $d$ RH are generally similar to those in CTL. A larger contribution from temperature $\left(d \mathrm{RH}_{T}\right)$ is found for temperature above $0{ }^{\circ} \mathrm{C}$ in NUG_UVTG. This may be a result of smaller contributions from either $d \mathrm{RH}_{q}$ or $d \mathrm{RH}_{q, T}$ due to the reduced water vapor bias. We also examined the in-cirrus microphysical properties simulated by these two new nudging experiments. The model features such as underestimations of $N_{i}$, IWC, and mean ice crystal size are similar to those in CTL and are not sensitive to the nudging strategy used.

\section{Discussion and conclusions}

In this study, we evaluated the macro- and microphysical properties of ice clouds simulated by CAM5 using in situ measurements from the HIPPO campaign. The HIPPO campaign sampled over the Pacific region from $67^{\circ} \mathrm{S}$ to $87^{\circ} \mathrm{N}$ across several seasons, making it distinctive from other previous campaigns and valuable for providing insight into evaluating model performance. To eliminate the impact of largescale circulation biases on the simulated cloud processes, we ran CAM5 using specified dynamics with simulated meteorology $(U, V$, and $T)$ nudged towards the GEOS-5 analysis while keeping water vapor, hydrometeors, and aerosols online-calculated by the model itself. Model results collocated with the flight tracks spatially and temporally were directly compared with the observations. Modeled cloud occurrences and in-cloud ice crystal properties were evaluated, and the reasons for the biases examined. We also examined the model sensitivity to $D_{\mathrm{cs}}$ and different parameterizations for ice nucleation.

The model can reasonably capture the vertical configuration and horizontal extension of specific cloud systems. In total, the model captures $79.8 \%$ of observed cloud occurrences within model grid boxes. For each cloud type, the model captures $94.3 \%$ of observed ice clouds, $86.1 \%$ of mixed-phase clouds, and $49.9 \%$ of warm clouds. This result is only modestly sensitive to whether meteorological fields ( $T$ and $Q$ ) are nudged. The model cannot capture the large spatial variability of observed RH, which is responsible for much of the model missing low-level warm clouds. A large portion of the RH bias results from the discrepancy in water vapor, with a small portion from the discrepancy in temperature. The model also underestimates the occurrence frequencies of ice supersaturation higher than $20 \%$ under clear-sky conditions (i.e., outside of cirrus clouds), which may indicate too low of a threshold for initiating heterogeneous ice nucleation in the model. In fact, a study comparing the observed RH distributions with real-case simulations of the Weather Research and Forecasting (WRF) model suggested that the threshold for initiating heterogeneous nucleation should be set at $\mathrm{RHi} \geq 125 \%$ (D'Alessandro et al., 2017).

Down to the micro-scale of cirrus clouds $\left(T \leq-40^{\circ} \mathrm{C}\right)$, the model captures well the decreasing trend of $\lambda$ with in- creasing temperature from -72 to $-40{ }^{\circ} \mathrm{C}$. However, the simulated $\lambda$ values are on average about $2-4$ times larger than observations at all the $4{ }^{\circ} \mathrm{C}$ temperature ranges for all the experiments with different $D_{\mathrm{cs}}$ and different ice nucleation parameterizations. This indicates that the model simulates a smaller mean size of ice crystals in each temperature range. The model is mostly able to reproduce the magnitude of observed $N_{i}$ (to within 1 order of magnitude) for ice crystals with diameters larger than $75 \mu \mathrm{m}$ yet generally underestimates $N_{i}$ except for the DCS75 simulation. Simulated $N_{i}$ is sensitive to $D_{\mathrm{cs}}$ and the number of sulfate aerosol particles for homogeneous nucleation used in the model. No apparent correlations between the mean $N_{i}$ and temperature are found in the observations, while a decrease of $N_{i}$ with increasing temperature is found in the two simulations (DCS300 and SUL). All the experiments underestimate the magnitude of IWC for ice crystals larger than $75 \mu \mathrm{m}$. The observations show an overall decreasing trend of IWC with decreasing temperature, while the model-simulated trends are not as strong. Simulated IWC is sensitive to $D_{\mathrm{cs}}$ but less sensitive to the different parameterizations of ice nucleation examined here.

Current climate models have typical horizontal resolutions of tens to hundreds of kilometers and are unable to represent the large spatial variability of environmental conditions for cloud formation and evolution within a model grid box. A previous study of Diao et al. (2014a) shows that the spatial variability of water vapor dominantly contributes to the spatial variability in $\mathrm{RH}$, compared with the contributions from those of temperature. Here our comparisons of model simulations with observations show that the biases in water vapor spatial distributions are the dominant sources of the model biases in RH spatial distributions. Thus it is a priority to develop parameterizations that are able to treat the sub-grid variability of water vapor for climate models. There are also substantial sub-grid variations of cloud microphysical properties shown in previous observational studies (e.g., Lebsock et al., 2013). Recently, a framework for treating the sub-grid variability of temperature, moisture, and vertical velocity has been developed and implemented into CAM5 (Bogenschutz et al., 2013). A multi-scale modeling framework has also been developed to explicitly resolve the cloud dynamics and cloud microphysics down to the scales of cloudresolving models (e.g., Wang et al., 2011; C. Zhang et al., 2014). The PDFs of sub-grid-scale distributions can be sampled on sub-columns for cloud microphysics (Thayer-Calder et al., 2015). With the increase of model resolutions for future global model developments, the sub-grid variability of temperature, moisture, and cloud microphysics and dynamics will be better resolved. In this study, we choose the resolution of $1.9^{\circ} \times 2.5^{\circ}$ because this resolution is still widely used in climate model simulations. We plan to evaluate the model performances at higher resolutions and to understand the resolution dependence of model results. 
Given the various environmental conditions and aerosol characteristics in the atmosphere, the formation and evolution of ice crystals are not well understood, and it is even more challenging for climate models to represent these processes. For the bulk ice microphysics used in our model, several assumptions have to be made to simulate both $N_{i}$ and $\lambda$. One of them is to partition the ice crystals into cloud ice and snow categories, while using $D_{\mathrm{cs}}$ to convert cloud ice to snow. Thus a more physical treatment of ice crystal evolution such as using bin microphysics (e.g., Bardeen et al., 2013; Khain et al., 2015) or a single category to represent all ice-phase hydrometeors (Morrison and Milbrandt, 2015; Eidhammer et al., 2017) is needed.

Data availability. The HIPPO observations are available at https: //www.eol.ucar.edu/field_projects/hippo (HIPPO, 2015). The modeled data used in this study are available upon request from the corresponding author X. Liu (xliu6@uwyo.edu).

Competing interests. The authors declare that they have no conflict of interest.

Acknowledgements. Xiaohong Liu and Chenglai Wu acknowledge support of the US Department of Energy's Atmospheric System Research Program (grant DE-SC0014239). The authors would like to acknowledge the use of computational resources (ark:/85065/d7wd3xhc) at the NCAR-Wyoming Supercomputing Center provided by the National Science Foundation (NSF) and the State of Wyoming, and supported by NCAR's Computational and Information Systems Laboratory. We appreciate the efforts of the NCAR Earth Observing Laboratory flight, technical, and mechanical crews during the NSF HIPPO Global campaign, in particular the PIs of the HIPPO Global campaign: S. Wofsy, R. Keeling, and B. Stephens. NCAR is sponsored by NSF. We acknowledge the support of the VCSEL hygrometer by Minghui Diao, M. Zondlo, and S. Beaton, and the support of the 2DC probe by A. Bansemer, C. J. Webster, and D. C. Rogers. We also acknowledge the funding of NSFAGS-1036275 for field support and data analyses from the VCSEL hygrometer in the HIPPO Global campaign. Minghui Diao gratefully acknowledges the support from the NCAR Advanced Study Program (ASP) postdoctoral fellowship in October 2013August 2015. Final data sets and documentation from the NSF HIPPO Global campaign can be accessed at http://hippo.ornl.gov in the Carbon Dioxide Information Analysis Center Data Archive at Oak Ridge National Laboratory. Kai Zhang was supported by the Office of Science of the US Department of Energy as part of the Earth System Modeling Program. PNNL is a multiprogram laboratory operated for DOE by Battelle Memorial Institute under contract DE-AC05-76RL01830. We thank T. Eidhammer from NCAR for her help on model result analysis.

Edited by: Q. Fu

Reviewed by: two anonymous referees

\section{References}

Abdul-Razzak, H. and Ghan, S. J.: A parameterization of aerosol activation, 2. Multiple aerosol types, J. Geophys. Res.-Atmos., 105, 6837-6844, 2000.

Bardeen, C. G., Gettelman, A., Jensen, E. J., Heymsfield, A., Conley, A. J., Delanoë, J., Deng, M., and Toon, O. B.: Improved cirrus simulations in a GCM using CARMA sectional microphysics, J. Geophys. Res., 118, 11679-11697, doi:10.1002/2013JD020193, 2013.

Bodas-Salcedo, A., Webb, M. J., Bony, S., Chepfer, H., Dufresne, J.-L., Klein, S. A., Zhang, Y., Marchand, R., Haynes, J. M., Pincus, R., and John, V. O.: COSP: A satellite simulation software for model assessment, Bull. Amer. Meteor. Soc., 92, 1023-1043, 2011.

Bogenschutz, P. A., Gettelman, A., Morrison, H., Larson, V. E., Craig, C., and Schanen, D. P.: Higher-Order Turbulence Closure and Its Impact on Climate Simulations in the Community Atmosphere Model, J. Clim., 26, 9655-9676, doi:10.1175/JCLI-D-1300075.1, 2013.

Boucher, O., Randall, D., Artaxo, P., Bretherton, C., Feingold, G., Forster, P., Kerminen, V.-M., Kondo, Y., Liao, H., Lohmann, U., Rasch, P., Satheesh, S. K., Sherwood, S., Stevens, B., and Zhang, X. Y.: Clouds and Aerosols, in: Climate Change 2013: The Physical Science Basis, Contribution of Working Group I to the Fifth Assessment Report of the Intergovernmental Panel on Climate Change, edited by: Stocker, T. F., Qin, D., Plattner, G.-K., Tignor, M., Allen, S. K., Boschung, J., Nauels, A., Xia, Y., Bex, V., and Midgley, P. M., Cambridge University Press, Cambridge, United Kingdom and New York, NY, USA, 1535, 571-657, 2013.

Bretherton, C. S. and Park, S.: A New Moist Turbulence Parameterization in the Community Atmosphere Model, J. Clim., 22, 3422-3448, doi:10.1175/2008JCLI2556.1, 2009.

Brown, P. R. A. and Francis, P. N.: Improved measurements of the ice water content in cirrus using a total-water probe, J. Atmos. Ocean. Tech., 12, 410-414, doi:10.1175/15200426(1995)0122.0.co;2, 1995.

Corti, T., Luo, B. P., Peter, T., Vömel, H., and Fu, Q.: Mean radiative energy balance and vertical mass fluxes in the equatorial upper troposphere and lower stratosphere, Geophys. Res. Lett., 32, L06802, doi:10.1029/2004GL021889, 2005.

D’Alessandro, J., Diao, M., Wu, C., Liu, X., Chen, M., Morrison, H., Eidhammer, T., Jensen, Jorgen B. Bansemer, A., Zondlo, M. A., and DiGangi, J. P.: Dynamical conditions of ice supersaturation in convective systems: a comparative analysis between in-situ aircraft observations and WRF simulations, J. Geophys. Res.-Atmos., 122, 2844-2866, doi:10.1002/2016JD025994, 2017.

DeMott, P. J., Cziczo, D. J., Prenni, A. J., Murphy, D. M., Kreidenweis, S. M., Thomson, D. S., Borys, R., and Rogers, D. C.: Measurements of the concentration and composition of nuclei for cirrus formation, P. Natl. Acad. Sci. USA, 100, 14655-14660, doi:10.1073/pnas.2532677100, 2003.

Deng, M. and Mace, G. G.: Cirrus Microphysical Properties and Air Motion Statistics Using Cloud Radar Doppler Moments, Part I: Algorithm Description, J. Appl. Meteorol. Climatol., 45, 16901709, doi:10.1175/JAM2433.1, 2006.

Deng, M. and Mace, G. G.: Cirrus Microphysical Properties and Air Motion Statistics Using Cloud Radar Doppler Moments, Part 
II: Climatology, J. Appl. Meteorol. Climatol., 47, 3221-3235, doi:10.1175/2008JAMC1949.1, 2008.

Diao, M., Zondlo, M. A., Heymsfield, A. J., Beaton, S. P., and Rogers, D. C.: Evolution of ice crystal regions on the microscale based on in situ observations, Geophys. Res. Lett., 40, 34733478, doi:10.1002/grl.50665, 2013.

Diao, M., Zondlo, M. A., Heymsfield, A. J., Avallone, L. M., Paige, M. E., Beaton, S. P., Campos, T., and Rogers, D. C.: Cloudscale ice-supersaturated regions spatially correlate with high water vapor heterogeneities, Atmos. Chem. Phys., 14, 2639-2656, doi:10.5194/acp-14-2639-2014, 2014a.

Diao, M., Zondlo, M. A., Heymsfield, A. J., and Beaton, S. P.: Hemispheric comparison of cirrus cloud evolution using in situ measurements in HIAPER Pole-to-Pole Observations, Geophys. Res. Lett., 41, 4090-4099, doi:10.1002/2014GL059873, 2014b.

Dinh, T., Fueglistaler, S., Durran, D., and Ackerman, T.: Cirrus and water vapour transport in the tropical tropopause layer - Part 2: Roles of ice nucleation and sedimentation, cloud dynamics, and moisture conditions, Atmos. Chem. Phys., 14, 12225-12236, doi:10.5194/acp-14-12225-2014, 2014.

Eidhammer, T., Morrison, H., Bansemer, A., Gettelman, A., and Heymsfield, A. J.: Comparison of ice cloud properties simulated by the Community Atmosphere Model (CAM5) with in-situ observations, Atmos. Chem. Phys., 14, 10103-10118, doi:10.5194/acp-14-10103-2014, 2014.

Eidhammer, T., Morrison, H., Mitchell, D., Gettelman, A., and Erfani, E.: Improvements in Global Climate Model Microphysics Using a Consistent Representation of Ice Particle Properties, J. Clim., 30, 609-629, doi:10.1175/jcli-d-16-0050.1, 2017.

Fusina, F., Spichtinger, P., and Lohmann, U.: Impact of ice supersaturated regions and thin cirrus on radiation in the midlatitudes, J. Geophys. Res.-Atmos., 112, D24S14, doi:10.1029/2007JD008449, 2007.

Gettelman, A. and Morrison, H.: Advanced Two-Moment Bulk Microphysics for Global Models, Part I: Off-Line Tests and Comparison with Other Schemes, J. Clim., 28, 1268-1287, doi:10.1175/JCLI-D-14-00102.1, 2015.

Gettelman, A., Randel, W. J., Wu, F., and Massie, S. T.: Transport of water vapor in the tropical tropopause layer, Geophys. Res. Lett., 29, 9-1-9-4, doi:10.1029/2001GL013818, 2002.

Gettelman, A., Liu, X., Ghan, S. J., Morrison, H., Park, S., Conley, A. J., Klein, S. A., Boyle, J., Mitchell, D. L., and Li, J. L. F.: Global simulations of ice nucleation and ice supersaturation with an improved cloud scheme in the Community Atmosphere Model, J. Geophys. Res.-Atmos., 115, D18216, doi:10.1029/2009JD013797, 2010.

Gettelman, A., Liu, X., Barahona, D., Lohmann, U., and Chen, C.: Climate impacts of ice nucleation, J. Geophys. Res.-Atmos., 117, D20201, doi:10.1029/2012JD017950, 2012.

Gettelman, A., Morrison, H., Santos, S., Bogenschutz, P., and Caldwell, P. M.: Advanced Two-Moment Bulk Microphysics for Global Models, Part II: Global Model Solutions and AerosolCloud Interactions, J. Clim., 28, 1288-1307, doi:10.1175/JCLID-14-00103.1, 2015.

Haag, W., Kärcher, B., Ström, J., Minikin, A., Lohmann, U., Ovarlez, J., and Stohl, A.: Freezing thresholds and cirrus cloud formation mechanisms inferred from in situ measurements of relative humidity, Atmos. Chem. Phys., 3, 1791-1806, doi:10.5194/acp3-1791-2003, 2003.
Heymsfield, A. J., Field, P., and Bansemer, A.: Exponential Size Distributions for Snow, J. Atmos. Sci., 65, 4017-4031, doi:10.1175/2008JAS2583.1, 2008.

Heymsfield, A. J., Schmitt, C., and Bansemer, A.: Ice cloud particle size distributions and pressure-dependent terminal velocities from in situ observations at temperatures from 0 to $-86^{\circ} \mathrm{C}$, J. Atmos. Sci., 70, 4123-4154, doi:10.1175/JAS-D-12-0124.1, 2013.

Hoose, C. and Möhler, O.: Heterogeneous ice nucleation on atmospheric aerosols: a review of results from laboratory experiments, Atmos. Chem. Phys., 12, 9817-9854, doi:10.5194/acp-12-98172012, 2012.

Hoyle, C. R., Luo, B. P., and Peter, T.: The Origin of High Ice Crystal Number Densities in Cirrus Clouds, J. Atmos. Sci., 62, 25682579, doi:10.1175/JAS3487.1, 2005.

Jensen, E. J., Diskin, G., Lawson, R. P., Lance, S., Bui, T. P., Hlavka, D., McGill, M., Pfister, L., Toon, O. B., and Gao, R.: Ice nucleation and dehydration in the Tropical Tropopause Layer, P. Natl. Acad. Sci. USA, 110, 2041-2046, doi:10.1073/pnas.1217104110, 2013.

Kärcher, B. and Spichtinger, B.: Cloud-controlling factors of cirrus, in: Clouds in the Perturbed Climate System: Their Relationship to Energy Balance, Atmospheric Dynamics, and Precipitation, edited by: Heintzenberg, J. and Charlson, R. J., Strüngmann Forum Report, The MIT Press, Cambridge, MA, USA, 3536, 235267, 2009.

Kay, J. E., Baker, M., and Hegg, D.: Microphysical and dynamical controls on cirrus cloud optical depth distributions, J. Geophys. Res.-Atmos., 111, D24205, doi:10.1029/2005JD006916, 2006.

Kay, J. E., Hillman, B. R., Klein, S. A., Zhang, Y., Medeiros, B., Pincus, R., Gettelman, A., Eaton, B., Boyle, J., Marchand, R., and Ackerman, T. P.: Exposing global cloud biases in the Community Atmosphere Model (CAM) using satellite observations and their corresponding instrument simulators, J. Clim., 25, 5190-5207, doi:10.1175/JCLI-D-11-00469.1, 2012.

Khain, A. P., Beheng, K. D., Heymsfield, A., Korolev, A., Krichak, S. O., Levin, Z., Pinsky, M., Phillips, V., Prabhakaran, T., Teller, A., van den Heever, S. C., and Yano, J. I.: Representation of microphysical processes in cloud-resolving models: Spectral (bin) microphysics versus bulk parameterization, Rev. Geophys., 53, 247-322, doi:10.1002/2014RG000468, 2015.

Koop, T., Luo, B., Tsias, A., and Peter, T.: Water activity as the determinant for homogeneous ice nucleation in aqueous solutions, Nature, 406, 611-614, 2000.

Kooperman, G. J., Pritchard, M. S., Ghan, S. J., Wang, M., Somerville, R. C. J., and Russell, L. M.: Constraining the influence of natural variability to improve estimates of global aerosol indirect effects in a nudged version of the Community Atmosphere Model 5, J. Geophys. Res., 117, D23204, doi:10.1029/2012JD018588, 2012.

Korolev, A. V., Emery, E. F., Strapp, J. W., Cober, S. G., Isaac, G. A., Wasey, M., and Marcotte, D.: Small Ice Particles in Tropospheric Clouds: Fact or Artifact? Airborne Icing Instrumentation Evaluation Experiment, B. Am. Meteorol. Soc., 92, 967-973, doi:10.1175/2010BAMS3141.1, 2011.

Krämer, M., Schiller, C., Afchine, A., Bauer, R., Gensch, I., Mangold, A., Schlicht, S., Spelten, N., Sitnikov, N., Borrmann, S., de Reus, M., and Spichtinger, P.: Ice supersaturations and cirrus cloud crystal numbers, Atmos. Chem. Phys., 9, 3505-3522, doi:10.5194/acp-9-3505-2009, 2009. 
Krämer, M., Rolf, C., Luebke, A., Afchine, A., Spelten, N., Costa, A., Meyer, J., Zöger, M., Smith, J., Herman, R. L., Buchholz, B., Ebert, V., Baumgardner, D., Borrmann, S., Klingebiel, M., and Avallone, L.: A microphysics guide to cirrus clouds - Part 1: Cirrus types, Atmos. Chem. Phys., 16, 3463-3483, doi:10.5194/acp16-3463-2016, 2016.

Lamarque, J. F., Emmons, L. K., Hess, P. G., Kinnison, D. E., Tilmes, S., Vitt, F., Heald, C. L., Holland, E. A., Lauritzen, P. H., Neu, J., Orlando, J. J., Rasch, P. J., and Tyndall, G. K.: CAM-chem: description and evaluation of interactive atmospheric chemistry in the Community Earth System Model, Geosci. Model Dev., 5, 369-411, doi:10.5194/gmd-5-369-2012, 2012.

Lawson, R. P.: Effects of ice particles shattering on the 2D-S probe, Atmos. Meas. Tech., 4, 1361-1381, doi:10.5194/amt-4-13612011, 2011.

Lebsock, M., Morrison, H., and Gettelman, A.: Microphysical implications of cloud-precipitation covariance derived from satellite remote sensing, J. Geophys. Res.-Atmos., 118, 6521-6533, doi:10.1002/jgrd.50347, 2013.

Li, J. L. F., Waliser, D. E., Chen, W. T., Guan, B., Kubar, T., Stephens, G., Ma, H. Y., Deng, M., Donner, L., Seman, C., and Horowitz, L.: An observationally based evaluation of cloud ice water in CMIP3 and CMIP5 GCMs and contemporary reanalyses using contemporary satellite data, J. Geophys. Res.-Atmos., 117, D16105, doi:10.1029/2012JD017640, 2012.

Liou, K.-N.: Influence of Cirrus Clouds on Weather and Climate Processes: A Global Perspective, Mon. Weather Rev., 114, 1167-1199, doi:10.1175/15200493(1986)114<1167:IOCCOW>2.0.CO;2, 1986.

Liu, X. and Penner, J. E.: Ice nucleation parameterization for global models, Meteorol. Z., 14, 499-514, 2005.

Liu, X., Penner, J. E., Ghan, S. J., and Wang, M.: Inclusion of Ice Microphysics in the NCAR Community Atmospheric Model Version 3 (CAM3), J. Clim., 20, 4526-4547, doi:10.1175/JCLI4264.1, 2007.

Liu, X., Easter, R. C., Ghan, S. J., Zaveri, R., Rasch, P., Shi, X., Lamarque, J. F., Gettelman, A., Morrison, H., Vitt, F., Conley, A., Park, S., Neale, R., Hannay, C., Ekman, A. M. L., Hess, P., Mahowald, N., Collins, W., Iacono, M. J., Bretherton, C. S., Flanner, M. G., and Mitchell, D.: Toward a minimal representation of aerosols in climate models: description and evaluation in the Community Atmosphere Model CAM5, Geosci. Model Dev., 5, 709-739, doi:10.5194/gmd-5-709-2012, 2012a.

Liu, X., Shi, X., Zhang, K., Jensen, E. J., Gettelman, A., Barahona, D., Nenes, A., and Lawson, P.: Sensitivity studies of dust ice nuclei effect on cirrus clouds with the Community Atmosphere Model CAM5, Atmos. Chem. Phys., 12, 12061-12079, doi:10.5194/acp-12-12061-2012, 2012 b.

Luebke, A. E., Afchine, A., Costa, A., Grooß, J.-U., Meyer, J., Rolf, C., Spelten, N., Avallone, L. M., Baumgardner, D., and Krämer, M.: The origin of midlatitude ice clouds and the resulting influence on their microphysical properties, Atmos. Chem. Phys., 16, 5793-5809, doi:10.5194/acp-16-5793-2016, 2016.

Mace, G. G., Zhang, Y., Platnick, S., King, M. D., Minnis, P., and Yang, P.: Evaluation of Cirrus Cloud Properties Derived from MODIS Data Using Cloud Properties Derived from GroundBased Observations Collected at the ARM SGP Site, J. Appl. Meteorol., 44, 221-240, doi:10.1175/JAM2193.1, 2005.
Morrison, H. and Gettelman, A.: A New Two-Moment Bulk Stratiform Cloud Microphysics Scheme in the Community Atmosphere Model, Version 3 (CAM3), Part I: Description and Numerical Tests, J. Clim., 21, 3642-3659, doi:10.1175/2008JCLI2105.1, 2008.

Morrison, H. and Milbrandt, J. A.: Parameterization of Cloud Microphysics Based on the Prediction of Bulk Ice Particle Properties, Part I: Scheme Description and Idealized Tests, J. Atmos. Sci., 72, 287-311, doi:10.1175/JAS-D-14-0065.1, 2015.

Murphy, D. M. and Koop, T.: Review of the vapour pressures of ice and supercooled water for atmospheric applications, Q. J. R. Meteorol. Soc., 131, 1539-1565, doi:10.1256/qj.04.94, 2005.

Neale, R. B. and Coauthors: Description of the NCAR Community Atmosphere Model (CAM 5.0), NCAR/TN-486+STR, available at: http://www.cesm.ucar.edu/models/cesm1.0/cam/docs/ description/cam5_desc.pdf (last access: 5 April 2017), 2012.

Park, S. and Bretherton, C. S.: The University of Washington Shallow Convection and Moist Turbulence Schemes and Their Impact on Climate Simulations with the Community Atmosphere Model, J. Clim., 22, 3449-3469, doi:10.1175/2008JCLI2557.1, 2009.

Park, S., Bretherton, C. S., and Rasch, P. J.: Integrating Cloud Processes in the Community Atmosphere Model, Version 5, J. Clim., 27, 6821-6856, doi:10.1175/JCLI-D-14-00087.1, 2014.

Ramanathan, V. and Collins, W.: Thermodynamic regulation of ocean warming by cirrus clouds deduced from observations of the 1987 El Nino, Nature, 351, 27-32, 1991.

Richter, J. H. and Rasch, P. J.: Effects of Convective Momentum Transport on the Atmospheric Circulation in the Community Atmosphere Model, Version 3, J. Clim., 21, 1487-1499, doi:10.1175/2007JCLI1789.1, 2008.

Shi, X., Liu, X., and Zhang, K.: Effects of pre-existing ice crystals on cirrus clouds and comparison between different ice nucleation parameterizations with the Community Atmosphere Model (CAM5), Atmos. Chem. Phys., 15, 1503-1520, doi:10.5194/acp15-1503-2015, 2015.

Tan, X., Huang, Y., Diao, M., Bansemer, A., Zondlo, M. A., DiGangi, J. P., Volkamer, R., and Hu, Y.: An assessment of the radiative effects of ice supersaturation based on in situ observations, Geophys. Res. Lett., 43, 11039-11047, doi:10.1002/2016GL071144, 2016.

Thayer-Calder, K., Gettelman, A., Craig, C., Goldhaber, S., Bogenschutz, P. A., Chen, C. C., Morrison, H., Höft, J., Raut, E., Griffin, B. M., Weber, J. K., Larson, V. E., Wyant, M. C., Wang, M., Guo, Z., and Ghan, S. J.: A unified parameterization of clouds and turbulence using CLUBB and subcolumns in the Community Atmosphere Model, Geosci. Model Dev., 8, 3801-3821, doi:10.5194/gmd-8-3801-2015, 2015.

Wang, M. and Penner, J. E.: Cirrus clouds in a global climate model with a statistical cirrus cloud scheme, Atmos. Chem. Phys., 10, 5449-5474, doi:10.5194/acp-10-5449-2010, 2010.

Wang, M., Ghan, S., Easter, R., Ovchinnikov, M., Liu, X., Kassianov, E., Qian, Y., Gustafson Jr., W. I., Larson, V. E., Schanen, D. P., Khairoutdinov, M., and Morrison, H.: The multiscale aerosol-climate model PNNL-MMF: model description and evaluation, Geosci. Model Dev., 4, 137-168, doi:10.5194/gmd-4137-2011, 2011.

Wang, M., Liu, X., Zhang, K., and Comstock, J. M.: Aerosol effects on cirrus through ice nucleation in the Community Atmosphere 
Model CAM5 with a statistical cirrus scheme, J. Adv. Model. Earth Syst., 6, 756-776, doi:10.1002/2014MS000339, 2014.

Wang, P.-H., Minnis, P., McCormick, M. P., Kent, G. S., and Skeens, K. M.: A 6-year climatology of cloud occurrence frequency from Stratospheric Aerosol and Gas Experiment II observations (1985-1990), J. Geophys. Res.-Atmos., 101, 2940729429, doi:10.1029/96JD01780, 1996.

Wang, Y. and Liu, X.: Immersion freezing by natural dust based on a soccer ball model with the Community Atmospheric Model version 5: climate effects, Environ. Res. Lett., 9, 124020, doi:10.1088/1748-9326/9/12/124020, 2014.

Wofsy, S. C.: HIAPER Pole-to-Pole Observations (HIPPO): finegrained, global-scale measurements of climatically important atmospheric gases and aerosols, Philos. T. R. Soc. A, 369, 2073 2086, doi:10.1098/rsta.2010.0313, 2011.

Wylie, D. P. and Menzel, W. P.: Eight Years of High Cloud Statistics Using HIRS, J. Clim., 12, 170-184, doi:10.1175/1520-044212.1.170, 1999 .

Zhang, C., Wang, M., Morrison, H., Somerville, R. C. J., Zhang, K., Liu, X., and Li, J. F.: Investigating ice nucleation in cirrus clouds with an aerosol-enabled multi-scale modeling framework, J. Adv. Model. Earth Syst., 6, 998-1015, doi:10.1002/2014MS000343, 2014.
Zhang, G. J. and McFarlane, N. A.: Sensitivity of climate simulations to the parameterization of cumulus convection in the Canadian Climate Centre general circulation model, Atmos. Ocean, 33, 407-446, 1995.

Zhang, K., Liu, X., Wang, M., Comstock, J. M., Mitchell, D. L., Mishra, S., and Mace, G. G.: Evaluating and constraining ice cloud parameterizations in CAM5 using aircraft measurements from the SPARTICUS campaign, Atmos. Chem. Phys., 13, 4963-4982, doi:10.5194/acp-13-4963-2013, 2013.

Zhang, K., Wan, H., Liu, X., Ghan, S. J., Kooperman, G. J., Ma, P. L., Rasch, P. J., Neubauer, D., and Lohmann, U.: Technical Note: On the use of nudging for aerosol-climate model intercomparison studies, Atmos. Chem. Phys., 14, 8631-8645, doi:10.5194/acp-14-8631-2014, 2014.

Zondlo, M. A., Paige, M. E., Massick, S. M., and Silver, J. A.: Vertical cavity laser hygrometer for the National Science Foundation Gulfstream-V aircraft, J. Geophys. Res.-Atmos., 115, D20309, doi:10.1029/2010JD014445, 2010. 